\title{
STUDY OF THE INFLUENCE OF UNDERLYING SOFT-SOIL LAYERS ON THE DYNAMIC AND EARTHQUAKE RESPONSE OF BELL TOWERS
}

\author{
G.C. Manos $^{1}$ \\ ${ }^{1}$ Emeritus Professor and Ex-Director of the Lab. of Strength of Materials and Structures, Aristotle \\ University \\ e-mail: gcmanos@civil.auth.gr
}

\begin{abstract}
The dynamic and earthquake response of a bell towers founded on soft soil layers is examined here. The dynamic and earthquake response of such a bell towers is numerically simulated together with a number of layers of the underlying soil. The earthquake response is examined for a variety of load combination conditions employing design spectra as well as the ground motion recorded at a small distance from this bell tower during a prototype earthquake motion. Towards this end, the variation of the recorded ground motion due to the flexibility of these underlying soil layers is also examined. The earthquake response is examined comparatively in terms of global response parameters, such as base shear, overturning moment, and top displacements as well as peak stress values at particular parts of the bell tower that stress concentration occurs. These response values are studied in a comparative way in order to validate these numerical simulations with the observed performance.
\end{abstract}

Keywords: Bell towers, In-situ Dynamic Measurements, Numerical Simulation, Earthquake Response, Soil-structure Interaction.

ISSN:2623-3347 C 2021 The Authors. Published by Eccomas Proceedia.

Peer-review under responsibility of the organizing committee of COMPDYN 2021.

doi: $10.7712 / 120121.8688 .19522$ 


\section{INTRODUCTION}

Bell towers are structures that are of particular interest regarding their dynamic and earthquake response, which has been the subject of research in the past. A large number of bell towers with dimensions much larger than the ones examined here are located in numerous cities in Italy and elsewhere. The largest percentage of these bell towers is built by stone or brick masonry. In many cases earthquake activity constitutes the major cause of serious damage for bell towers that many times leads to partial or total collapse ([1] to [16]). Consequently, there is a major international concern for the stability of numerous bell towers. This resulted to significant international research effort that includes in-situ monitoring of the response of bell towers on a temporary basis, like the one attempted here, or more sophisticated and on a permanent basis Foundation problems for bell towers are evident in many case the most celebrated being Pisa's grand bell tower in Italy, that is quoted as a major medieval engineering error. Therefore, the soil flexibility is also an area of research interest for these structures especially when their dynamic and earthquake response is under investigation ([19] to [28].

This investigation was initiated by the observed performance of two relatively new bell towers. Both these bell towers, built by reinforced concrete (RC) and founded on an RC foundation block did not sustain any structural damage. They were both founded on relatively flexible soil although they were not any visible signs of soil deformation at the aftermath of the strong seismic ground motion. For both towers in-situ measurements were performed aiming to investigate their main dynamic characteristics. From these measurements it became apparent that the flexibility of the underlying soil layers could have exerted an influence on the seismic performance of these bell towers that should not be ignored. This was initially attempted by altering the flexibility of the supports of the RC foundation block utilizing linearly flexible links between the foundation block and the underlying soil. This was successful, up to a point, as shown by comparing the numerically predicted in this way fundamental translational periods of these bell towers to the corresponding values found from the in-situ measuring campaign. However, in this way the adopted approach did not address the influence of the existing structures to the assumed earthquake ground motion, which was recorded at some distance from these structures which were of considerable height $(23 \mathrm{~m})$ with a foundation block of considerable dimensions ( $4.5 \mathrm{~m}$ x $4.5 \mathrm{~m}$ in plan and more than $1 \mathrm{~m}$ thick). Moreover, it was interesting to observe that in the case of one of these bell towers (Havriata) the nearby church was damaged as well as the South slope of the hill that both the bell tower and the church were located showed signs of distress (see figures 1). In what follows, an investigation is performed aimed to study the bell tower dynamic and earthquake response by numerically simulating the structure of the bell tower and its foundation together with a considerable volume of the underlying soil. This investigation, for simplicity purposes, is performed in the 2$\mathrm{D}$ domain and assumes linear behaviour of both the soil and the superstructures. At a later stage, this study can be extended at a later stage to a more complex numerical simulation in the 3-D domain which could also include a more realistic behaviour of the soil volume than that which is assumed at present. In what follows initially the acceleration at the bedrock is approximated. Next, the response of the soil volume is studied in three different configurations; the first assumes only the given soil volume the second this soil volume with a simple superstructure numerically simulating the church and the third configuration includes the given soil volume together with simple numerical simulations of both the church and the bell tower. The obtained numerical predictions are presented and discussed. 


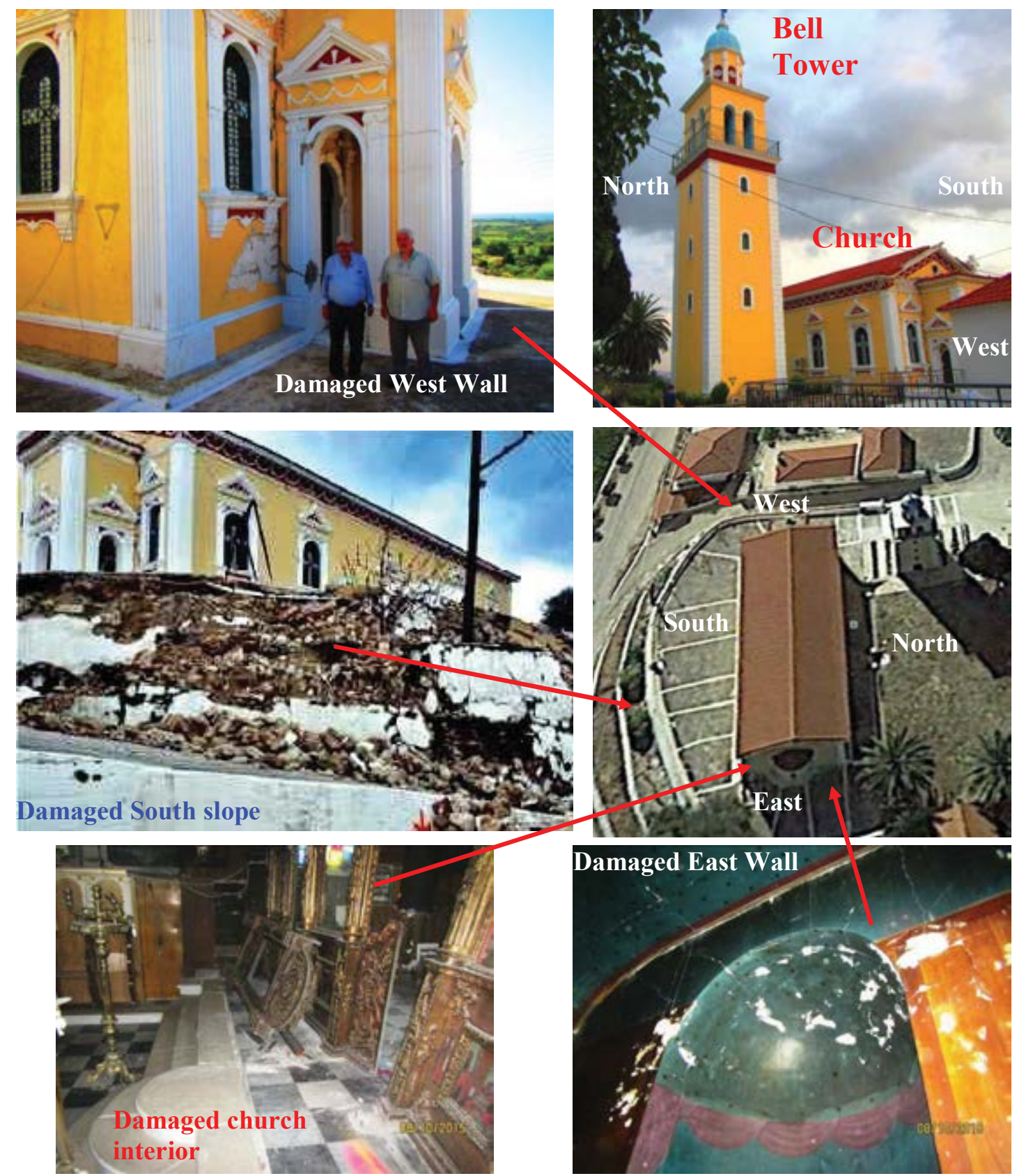

Fig. 1. The Church and the bell tower of the Panagia Agriliotissa at Havriata, Kefalonia-Greece together with the interior and exterior damage of the church and the South slope.

\section{ESTIMATING THE ROCK ACCELERATION.}

In what follows a study is performed using the ground acceleration (figure 2) recorded during the 3rd of February 2014 earthquake sequence at Havriata village in Kefalonia island [3]. The two horizontal and the vertical components of this record are used as input together with a soil volume that is assumed to be $30 \mathrm{~m}$ deep. For layers deeper than $30 \mathrm{~m}$ it is assumed that these layers have mechanical properties close to those of a rocky formation. The soil volume above this rocky substrate is divided in three layers having a $10 \mathrm{~m}$ depth each. Three dif- 
ferent soil profiles are studied whereby the properties of the upper layer are only varied whereas the properties of the other two underlying layers remain constant. Two types of analyses are performed using a 2-D software for this purpose. The first type of analysis assumes linear behaviour of the soil volume that depends on the given elastic mechanical properties of the soil layers. The second type of analysis assumes a certain soil non-linear behaviour as it is simulated by given options in this software [17].

\subsection{Linear behaviour of the underlying soil layers.}

Initially, linear behaviour of the underlying soil layers are assumed with elastic properties listed in table 1. The following values of the soil properties are listed in this table. Young's Modulus E (Mpa), Shear Modulus G (Mpa), Mass density $\boldsymbol{\rho}(\mathrm{KNsec} 2 / \mathrm{m} 4)$, and Shear wave velocity $\boldsymbol{v}(\mathrm{m} / \mathrm{sec})$ given by equation 1 .

$$
v=(G / \rho))^{0.5}
$$

\begin{tabular}{|c|c|c|c|c|c|}
\hline $\begin{array}{c}\text { Depth } \\
(\mathrm{m})\end{array}$ & Soil Profiles & $\begin{array}{c}\mathbf{E} \\
(\mathrm{MPa})\end{array}$ & $\begin{array}{c}\mathbf{G} \\
(\mathrm{MPa})\end{array}$ & $\begin{array}{c}\boldsymbol{\rho} \\
\left(\mathrm{KNsec} / \mathrm{m}^{4}\right)\end{array}$ & $\begin{array}{c}\mathbf{v} \\
(\mathrm{m} / \mathrm{sec})\end{array}$ \\
\hline 0 to -10 & $1^{\text {st }}$ Profile & 465 & 194 & 1.835 & 325 \\
\hline 0 to -10 & $2^{\text {nd }}$ Profile & 300 & 125 & 1.835 & 261 \\
\hline 0 to -10 & $3^{\text {rd }}$ Profile & 100 & 41.67 & 1.835 & 150 \\
\hline-10 to -20 & $1^{\text {st }}, 2^{\text {nd }}$ and $3^{\text {rd }}$ Profiles & 1000 & 417 & 1.835 & 477 \\
\hline-20 to -30 & $1^{\text {st }}, 2^{\text {nd }}$ and $3^{\text {rd }}$ Profiles & 2000 & 833 & 1.835 & 674 \\
\hline Deeper than $-30 \mathrm{~m}$ & $1^{\text {st }}, 2^{\text {nd }}$ and $3^{\text {rd }}$ Profiles & 50000 & 20833 & 1.835 & 1066 \\
\hline
\end{tabular}

Table 1. Elastic properties of the soil layers

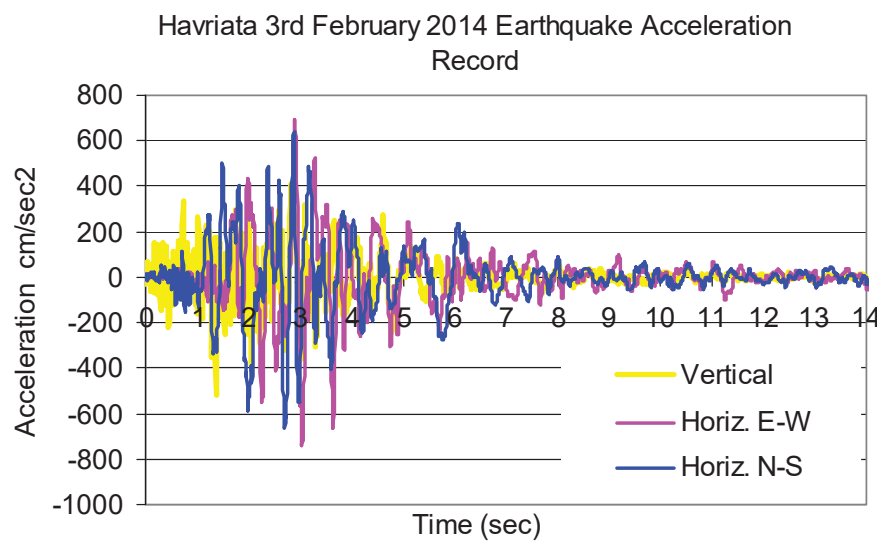

Figure 2. The recorded at Havriata earthquake ground motion in terms of two horizontal and the vertical acceleration components.

In what follows, the software STRATA [17] assuming linear behaviour of all the under lying soil layers with values of these elastic properties listed in table 1. Based on these values and using as input information the acceleration components of the recorded ground motion at the surface of the Havriata town the corresponding components are obtained at bedrock, assumed to be at layers deeper than $30 \mathrm{~m}$ from the soil surface. The results are obtained in two forms, either as acceleration time history or as the relevant acceleration elastic response spectral curve (for 5\% damping ratio). Along these lines a parametric study is performed whereby the 3 three soil profiles listed in table 1 were analyzed. The obtained results in terms of either acceleration time history components at bedrock or acceleration elastic response spectral curves (for 5\% damping ratio) are depicted in 
figure 2 (soil profile 1) for the two horizontal and the vertical component of the Havriata $3^{\text {rd }}$ of February 2014 record of the earthquake ground motion. For soil profiles 2 and 3 the corresponding results are depicted in figures 3 and 4, respectively. As it is listed in figures 2, 3 and 4 as well as from the values listed in Table 1 soil profile 1 corresponds to a relatively stiff soil, soil profile 2 to a moderately stiff soil whereas soil profile 3 corresponds to a relatively flexible soil.
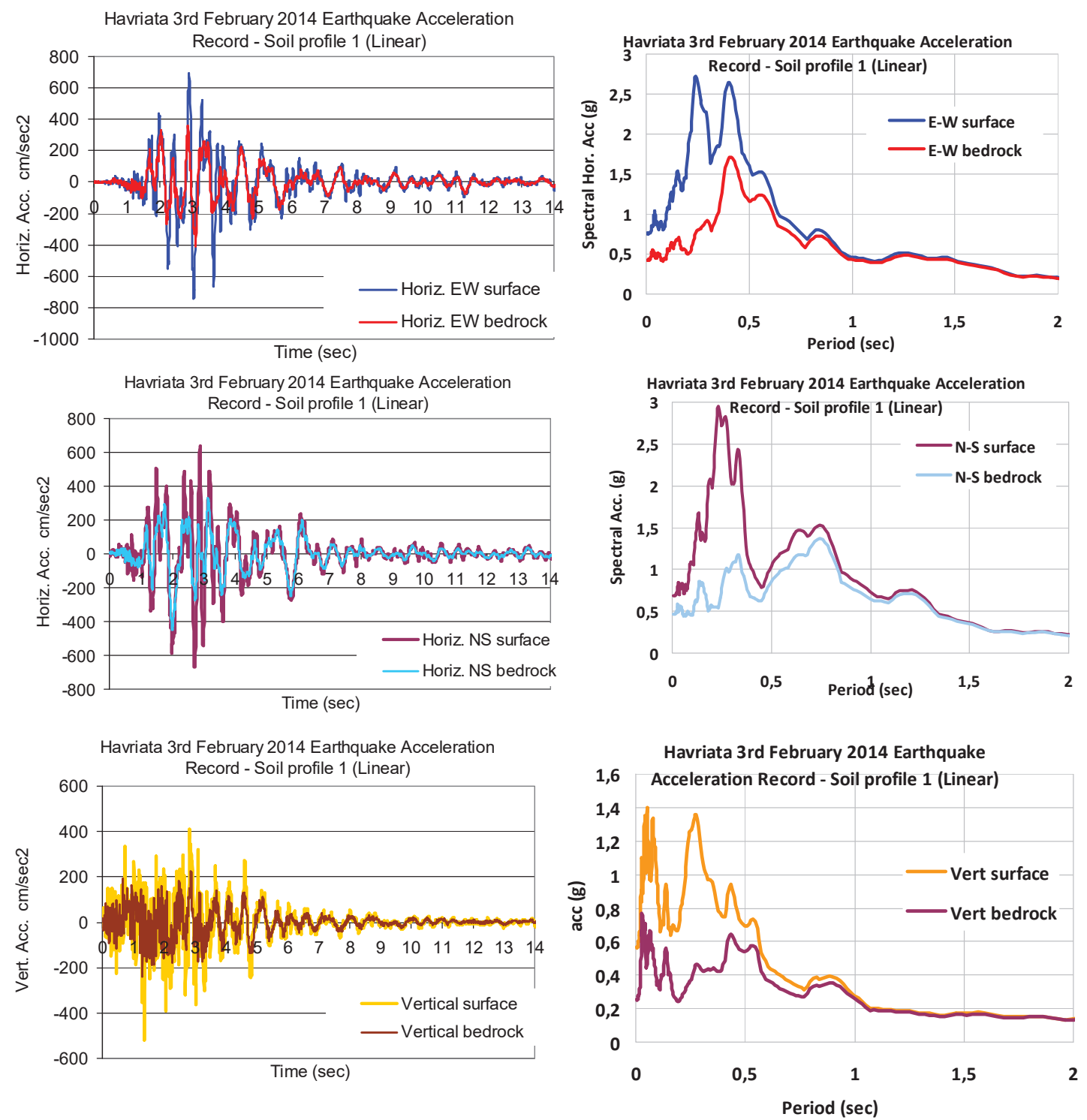

Figure 2. The obtained acceleration components at the bedrock for the Havriata earthquake ground motion in terms of two horizontal and the vertical acceleration components or the corresponding elastic response spectral curves (for 2\% damping ratio). Soil Profile 1 (Linear) Upper laver relatively stiff. 

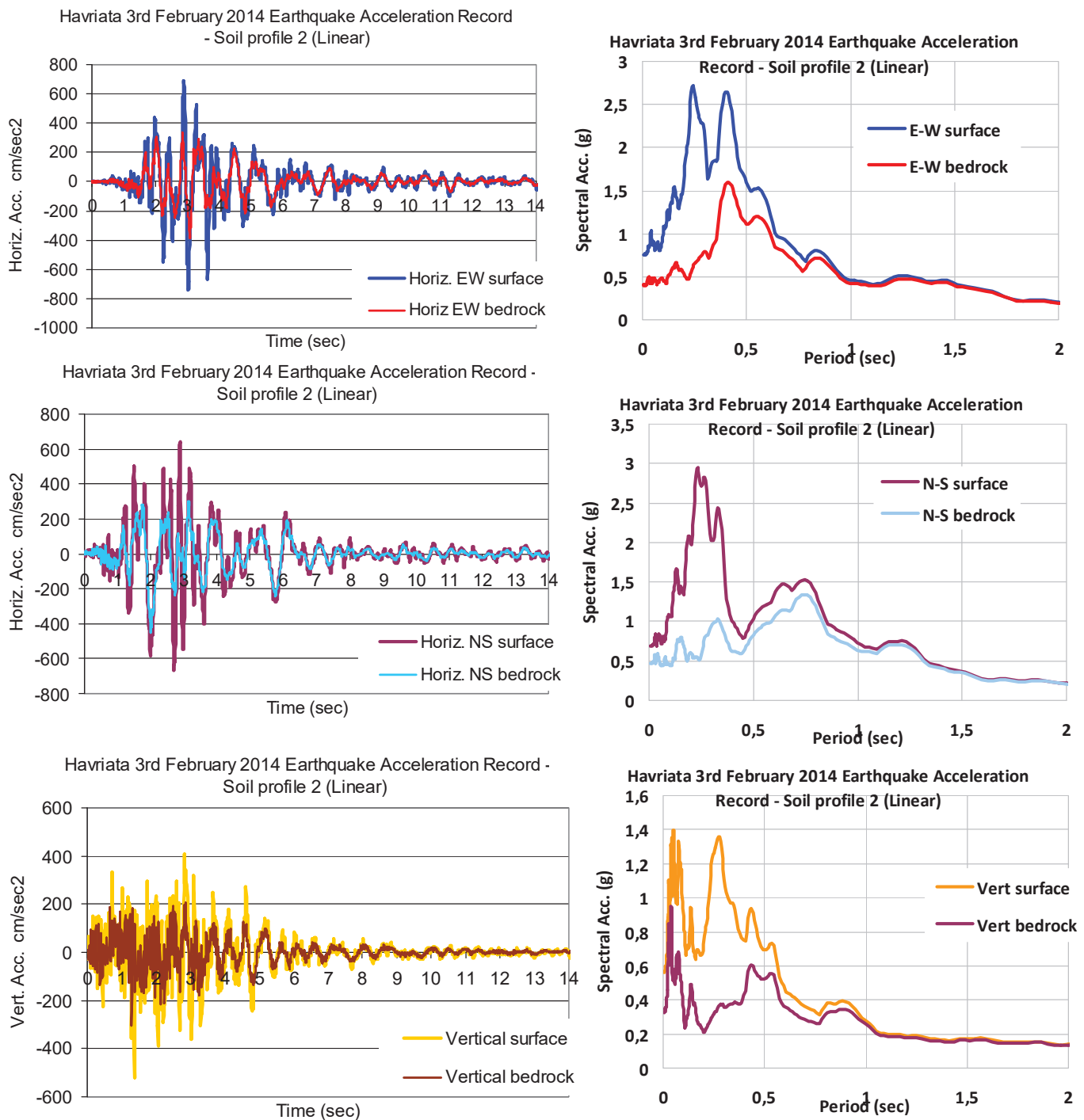

Figure 3. The obtained acceleration components at the bedrock for the Havriata earthquake ground motion in terms of two horizontal and the vertical acceleration components or the corresponding elastic response spectral curves (for $2 \%$ damping ratio). Soil Profile 2 (Linear) Upper laver moderately flexible.
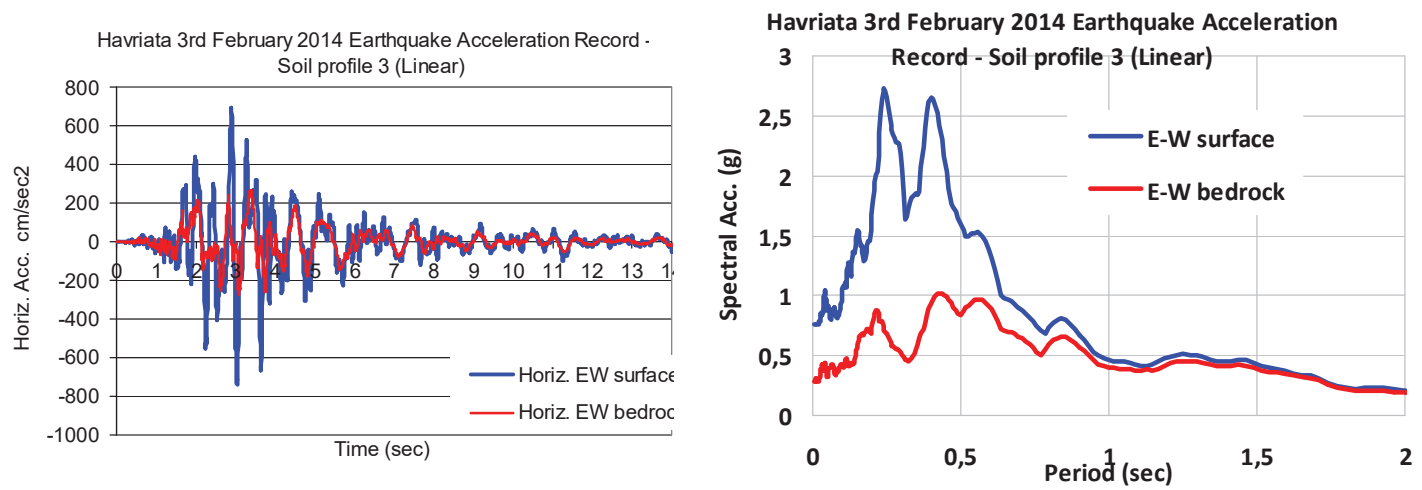

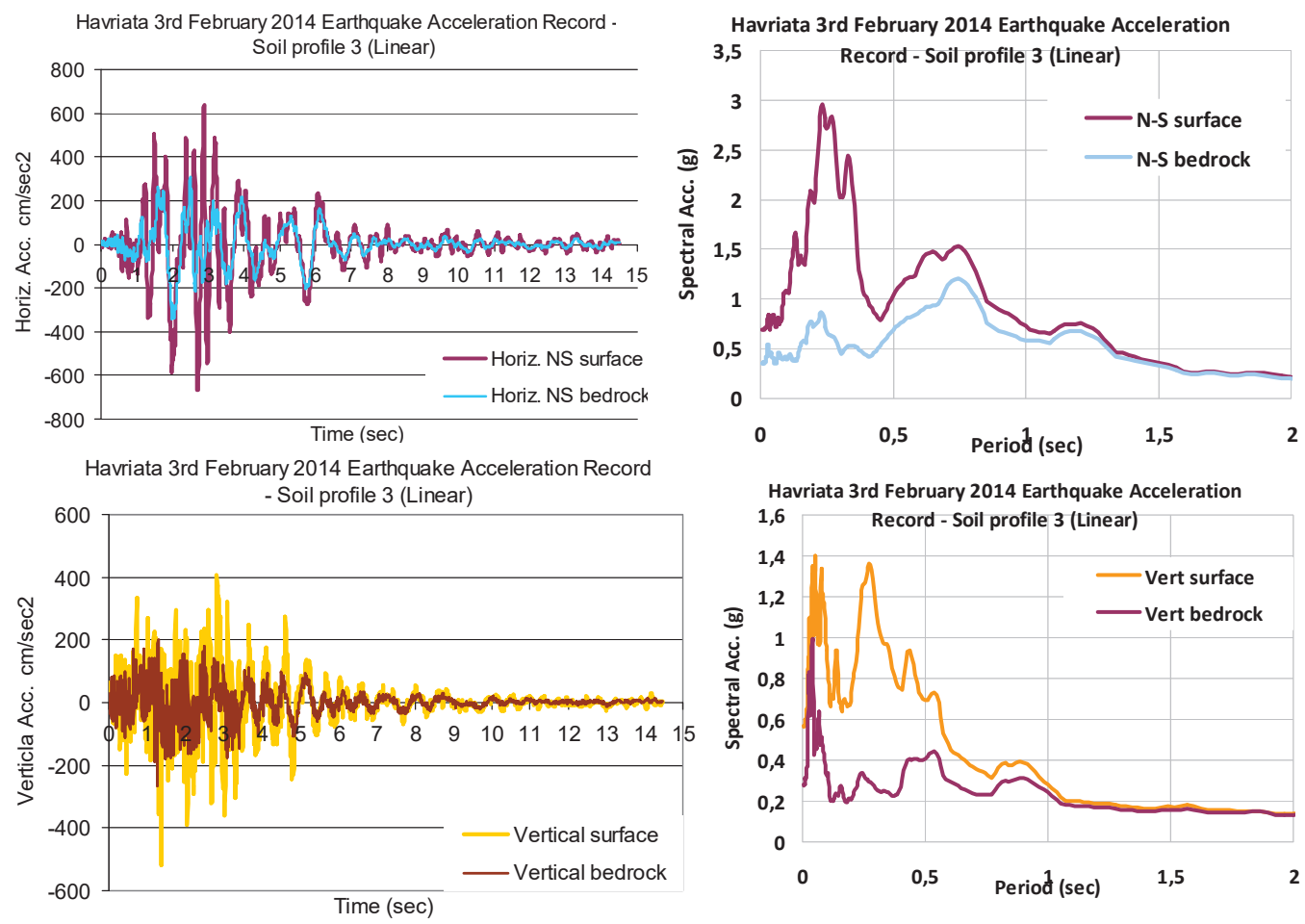

Figure 4. The obtained acceleration components at the bedrock for the Havriata earthquake ground motion in terms of two horizontal and the vertical acceleration components or the corresponding elastic response spectral curves (for 2\% damping ratio). Soil Profile 3 (Linear) Upper laver relativelv flexible.
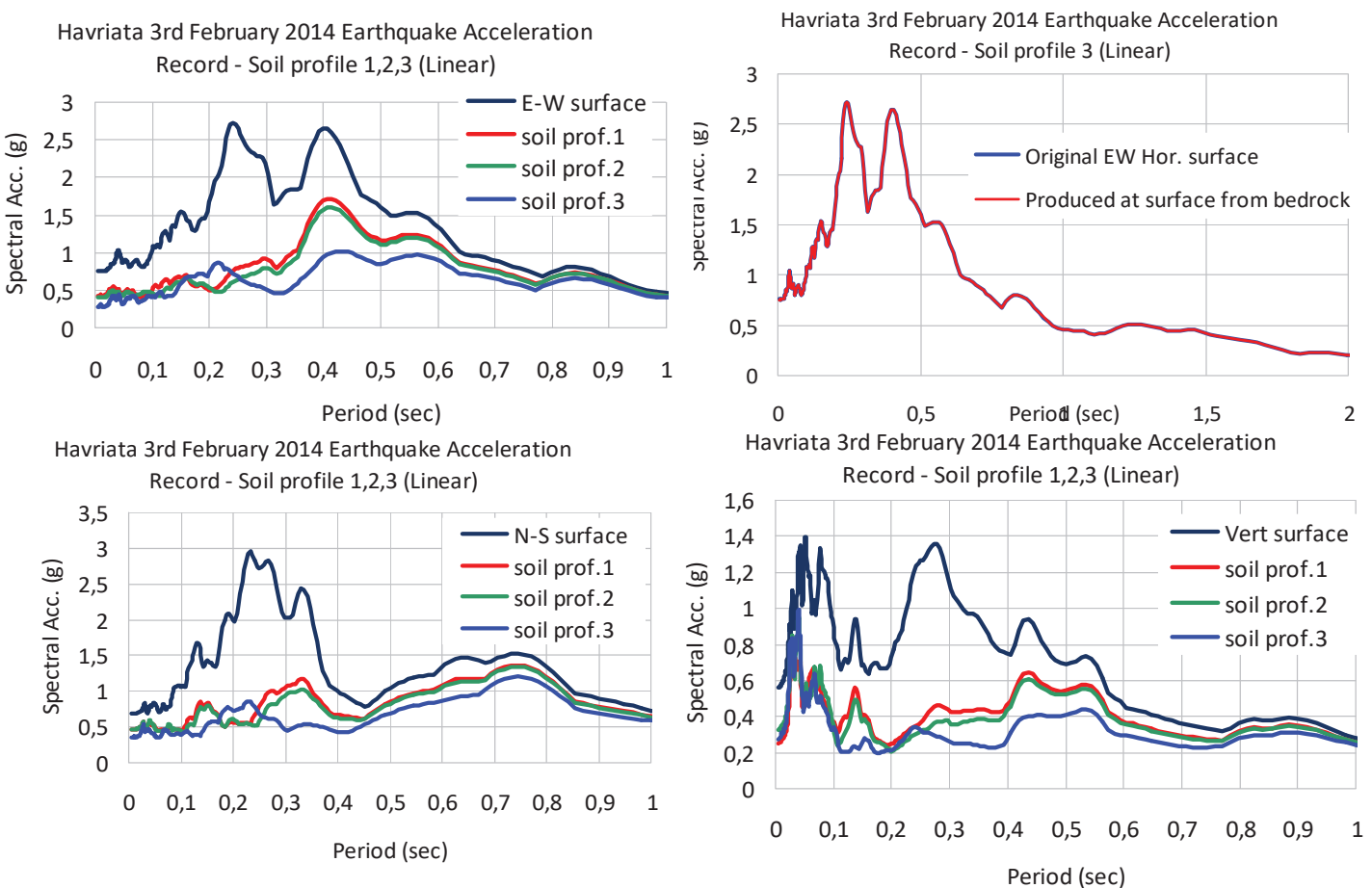

Figure 5. Comparison of the acceleration spectral curves obtained from the recorded components of the seismic ground motion at Havriata and the corresponding acceleration spectral curves from the acceleration components obtained from STRATA software at the bedrock for the three soil profiles. 
Figure 5 summarizes the results of figures 2, 2 and 4 in terms of acceleration spectral curves derived from the acceleration components obtained at bedrock by utilizing STRATA software assuming soil properties for three soil profiles listed in table 1 and assuming linear behaviour. In the same figures the spectral curves at the surface of the soil volume derived from the three components of the recorded seismic ground motion at Havriata are also plotted. Moreover, at the top right of this figure the spectral curve of the East-West component of the recorded during the seismic event ground motion is compared with the corresponding spectral curve found by applying the STRATA software in the inverse way. That is, using as bedrock acceleration the one found for soil profile 3 is used as input to obtain through this software the acceleration at the surface of the soil-volume. Then, the spectral acceleration curve for $5 \%$ damping ratio is found and potted. As can be seen, these two spectral acceleration curves, the original one from the actual record and the one employing STRATA software, combining the direct and the inverse process, are identical. Moreover, from the results depicted in figures 2, 3,4 and 5 it can be seen that that both the acceleration time histories and the corresponding acceleration spectral curves are deflated when they are compared with the corresponding values at the soil volume surface of the originally recorded ground acceleration. It can also be observed, that this deflation, is larger for soil profile 3 than for either soil profile 2 or soil profile 1. Inversely, the more flexible the soil profile the more intense the amplification of the ground acceleration at the surface either in terms of time history or acceleration spectral values.

\subsection{Non-Linear behaviour of the underlying soil layers}

The linear analyses with the STRAT software, previously described, were followed by additional analyses assuming non-linear properties for the underlying soil layers. Two additional soil profiles were used here, as a non-linear variation of the linear $3^{\text {rd }}$ soil profile listed in table 1 . First, the $4^{\text {th }}$ soil profile is formed by assuming at the upper soil layer ( 0 to $\left.-10 \mathrm{~m} \mathrm{depth}\right)$ the soil properties representative of "Imperial Valley soil", which is an option included in the software and represents relatively stiff soil. Next, the $5^{\text {th }}$ soil profile is formed by assuming at the upper soil layer ( 0 to $-10 \mathrm{~m}$ depth) the soil properties representative of the "Idriss weak clay", which is another option included in the software and represents relatively flexible soil. These two soil profiles are listed in table 2. Again, the properties of the layers deeper than $10 \mathrm{~m}$ are the same for both the $4^{\text {th }}$ and the $5^{\text {th }}$ soil profile as listed in table 2. In reference [18] a study on the influence of the plasticity index (PI) on the cyclic stress-strain parameters of saturated soils needed for site-response evaluations and seismic microzonation is presented. Ready-to-use charts are included, showing the effect of PI on the location of the modulus reduction curve G/Gmax versus cyclic shear strain $\gamma c$, and on the material damping ratio $\lambda$ versus $\gamma c$ curve. The charts are based on experimental data from 16 publications encompassing normally and overconsolidated clays (OCR $=1-15)$, as well as sands. It is shown that PI is the main factor controlling $\mathrm{G} / \mathrm{Gmax}$ and $\lambda$ for a wide variety of soils; if for a given $\gamma \mathrm{c}$ PI increases, $\mathrm{G} / \mathrm{Gmax}$ rises and $\lambda$ is reduced. Similar evidence is presented showing the influence of PI on the rate of modulus degradation with the number of cycles in normally consolidated clays. It is concluded that soils with higher plasticity tend to have a more linear cyclic stress-strain response at small strains and to degrade less at larger $\gamma \mathrm{c}$ than soils with a lower PI. Possible reasons for this behavior are discussed. A parametric study is presented showing the influence of the plasticity index on the seismic response of clay sites excited by the accelerations recorded on rock in Mexico City during the 1985 earthquake". For the $4^{\text {th }}$ and $5^{\text {th }}$ soil profiles the nonlinear variation of the assumed shear modulus and damping depending on the strain amplitude is depicted in figures 5 and 6 . 


\begin{tabular}{|c|c|c|}
\hline $\begin{array}{c}\text { Layer No. } \\
\text { Depth (m) }\end{array}$ & $\begin{array}{c}4^{\text {th }} \text { Non-linear Profile } \\
\text { Relatively stiff soil }\end{array}$ & $\begin{array}{c}5^{\text {th }} \text { Non-linear Profile Rela- } \\
\text { tively flexible soil }\end{array}$ \\
\hline Layer 1 (0 to10m) & Imperial Valley (Soils 0-300ft) & Idriss, Weak-Clay \\
\hline Layer 2 (-10m to -20m) & Vucetic \& Dobry PI=100 & Vucetic \& Dobry PI=100 \\
\hline Layer 3 (-20m to -30m) & Vucetic \& Dobry PI $=200$ & Vucetic \& Dobry PI=200 \\
\hline
\end{tabular}

Table 2. Non-linear soil profiles $4^{\text {th }}$ and $5^{\text {th }}$.
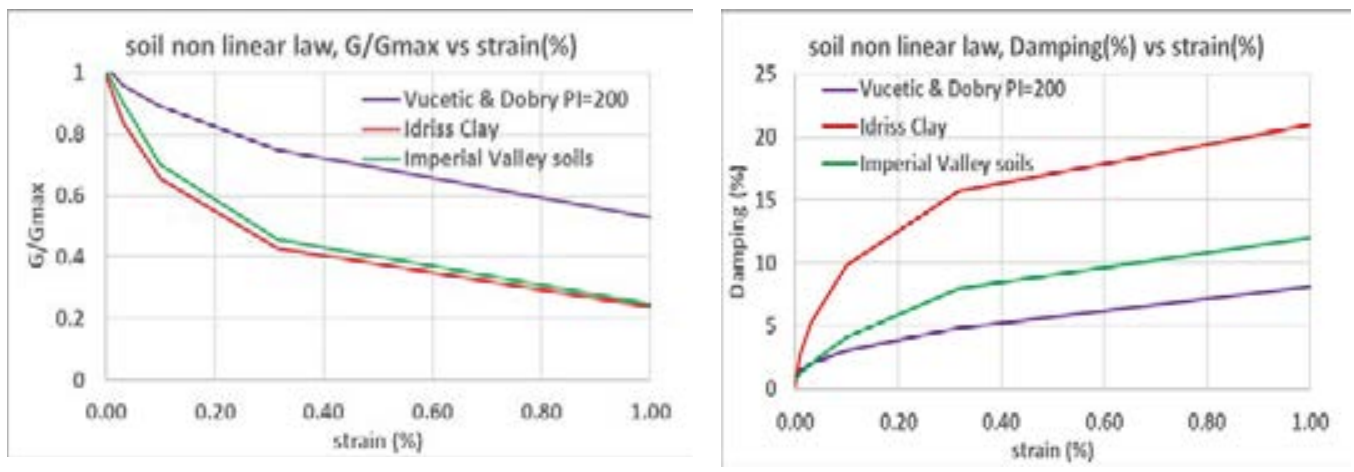

Figure 6. The assumed non-linear variation of the shear modulus with strain amplitude (left). The assumed nonlinear variation of the damping ratio with strain amplitude (right).
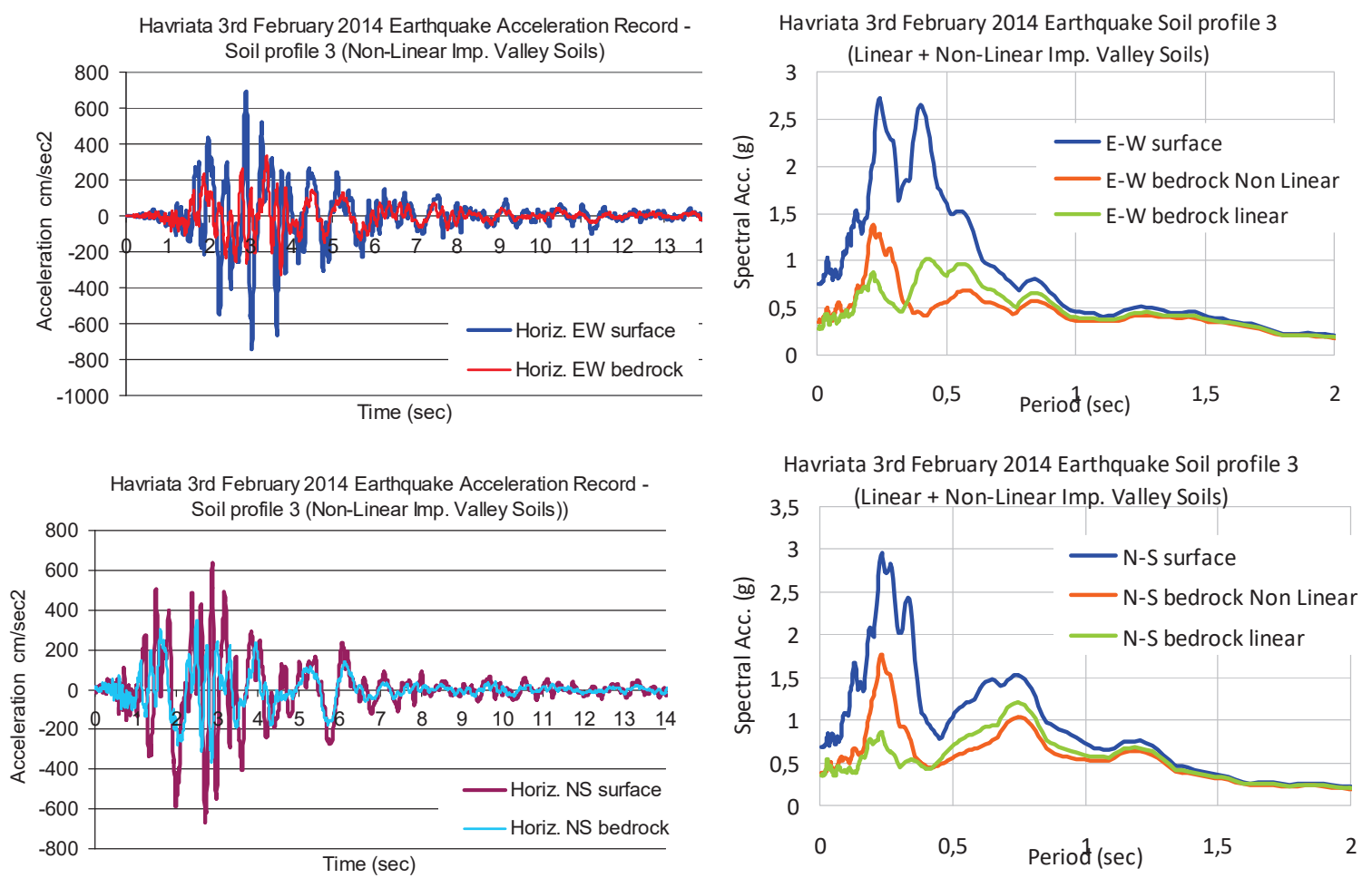

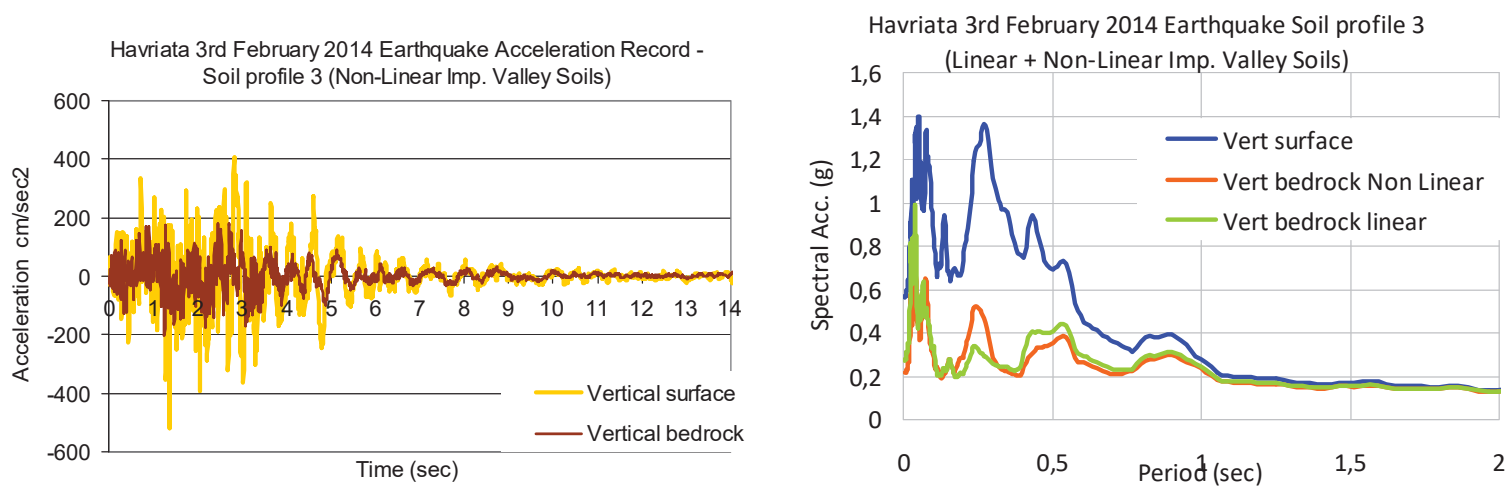

Figure 7. The obtained acceleration components at the bedrock for the Havriata earthquake ground motion in terms of two horizontal and the vertical acceleration components or the corresponding elastic response spectral curves (for $2 \%$ damping ratio). Soil Profile $4^{\text {th }}$ (Non-Linear) Upper laver relatively stiff.
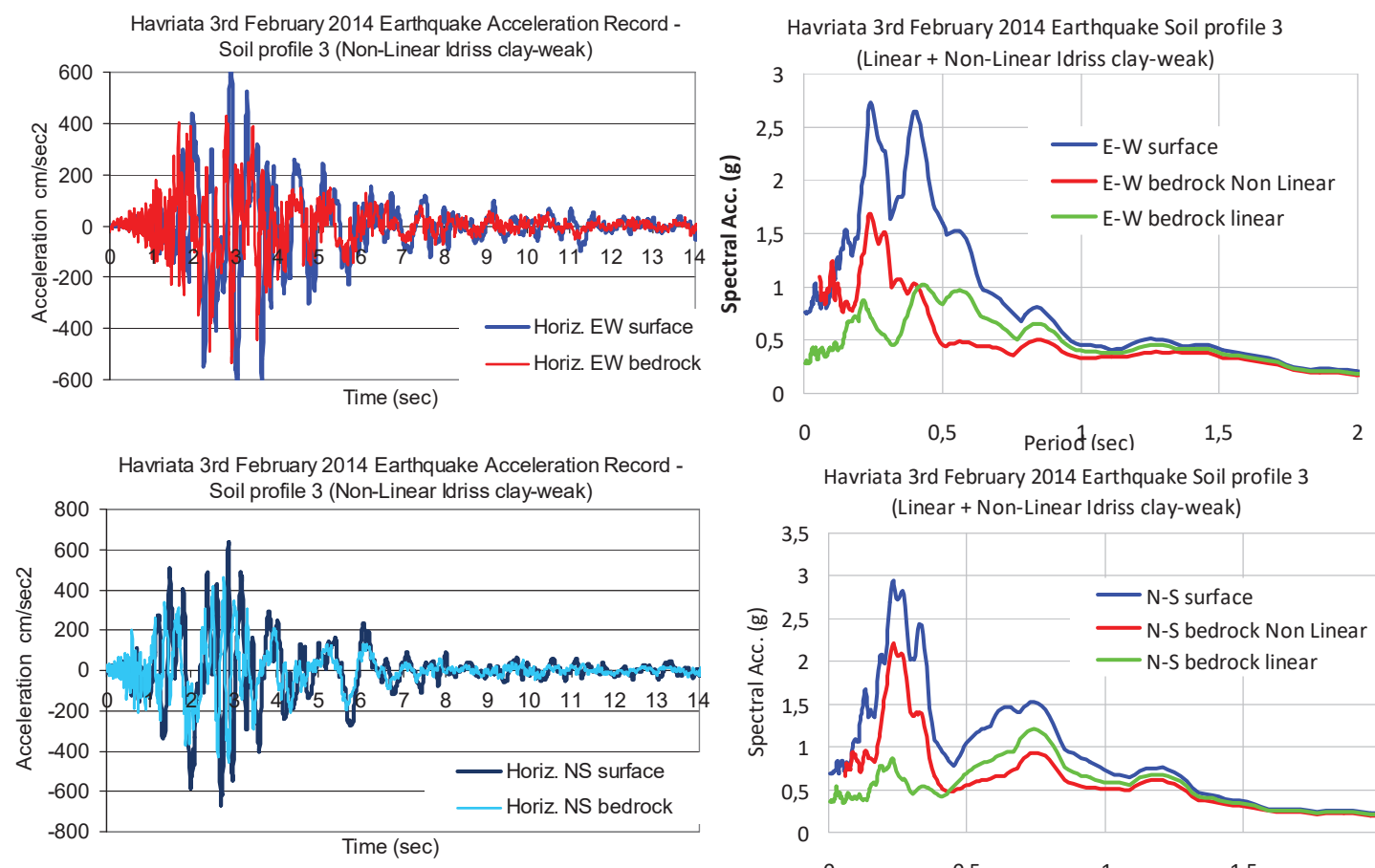

Havriata 3rd February 2014 Earthquake Soil profile 3 (Linear + Non-Linear Idriss clay-weak)

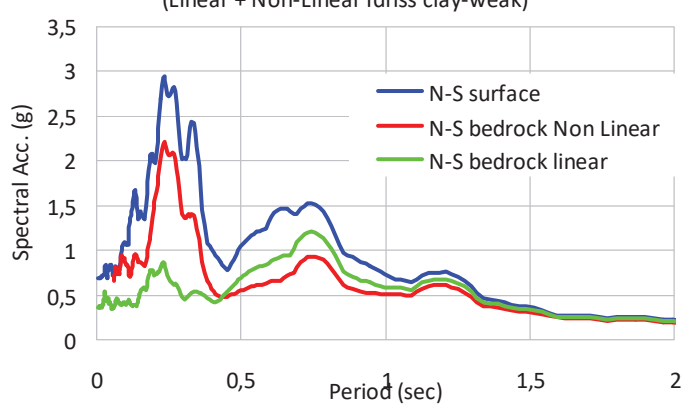

Havriata 3rd February 2014 Earthquake Acceleration Record Soil profile 3 (Non-Linear Idriss clay-weak)

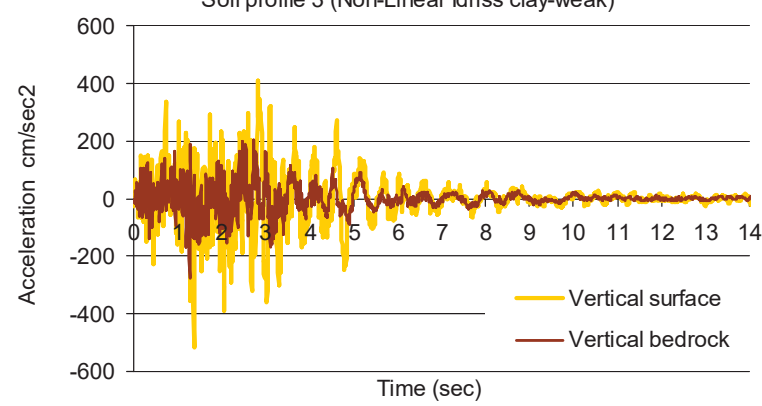

Havriata 3rd February 2014 Earthquake Soil profile 3 (Linear + Non-Linear Idriss clay-weak)

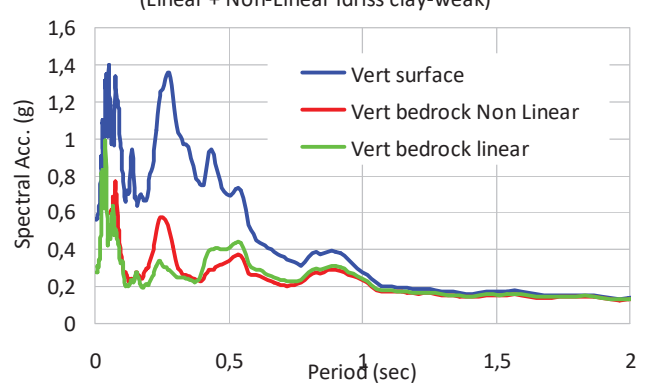

Figure 8. The obtained acceleration components at the bedrock for the Havriata earthquake ground motion in terms of two horizontal and the vertical acceleration components or the corresponding elastic response spectral curves (for 2\% damping ratio). Soil Profile $5^{\text {th }}$ (Non-Linear) Upper laver relativelv flexible. 
The obtained acceleration at bed rock, in terms of either acceleration time histories or response spectral curves are depicted in figures 7 and 8 for soil profiles $4^{\text {th }}$ and $5^{\text {th }}$, respectively. In the spectral curves plots the corresponding spectral curves for soil profile 3 assuming linear behaviour are also plotted. In the same plots the corresponding seismic ground acceleration recorded during the February 2014 earthquake sequence, either in terms of time history or in terms of the corresponding acceleration spectral curves for $5 \%$ damping ratio are also shown. Moreover, in figure 9 the spectral curve of the East-West component of the recorded during the seismic event ground motion is compared with the corresponding spectral curve found by applying the STRATA software in the inverse way. That is, using as bedrock acceleration the one found for soil profile 4 (left of figure 9) or soil profile 5 (right of figure 9) is used as input to obtain through this software the acceleration at the surface of the soil-volume. Then, the spectral acceleration curve for 5\% damping ratio is found and plotted in this figure. As can be seen, these two spectral acceleration curves, the original one from the actual record and the one employing STRATA software, combining the direct and the inverse process, are differing with the best agreement achieved for soil profile 5. As was observed from the results obtained assuming linear behaviour from the results depicted in figures 7 and 8 it can be seen that that assuming non-linear behaviour both the acceleration time histories and the corresponding acceleration spectral curves are deflated when they are compared with the corresponding values at the soil volume surface from the originally recorded ground motion. It can also be observed, that for small eigen-period values $(0.1$ to $0.4 \mathrm{sec})$ this deflation, is smaller when assuming non-linear (soil profiles 4 and 5) than when assuming linear behaviour (soil profile 3). Inversely, the non-linear soil behaviour the less intense the amplification of the ground acceleration at the surface either in terms of acceleration spectral values for small eigen-period values $(0.1$ to $0.4 \mathrm{sec})$. The opposite is true for relatively large period values $(0.4$ to $1.0 \mathrm{sec}$ ). Following the inverse approach for soil profile 4 and 5 and assuming non-linear behaviour it can be seen that for soil profile 5 (figure 9, right) the predicted spectral values in the period range from $0.3 \mathrm{sec}$ to $0.4 \mathrm{sec}$ there are amplified when compared with the corresponding values of the original record. The opposite is true for soil profile 4 (figure 9 , left).
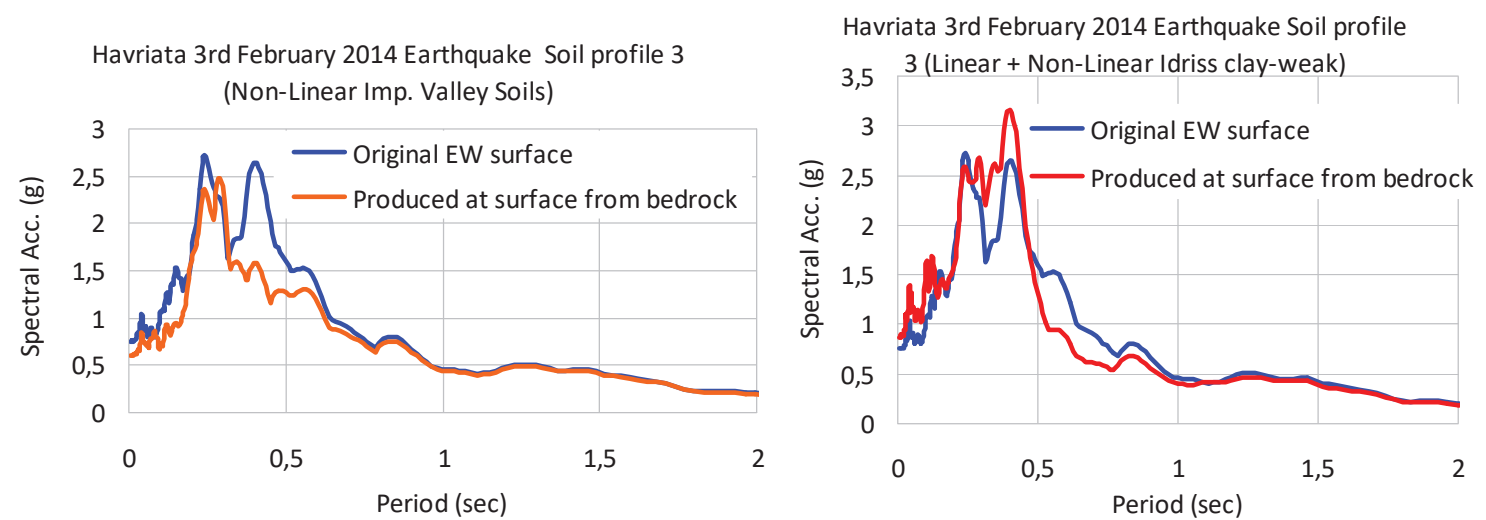

ground motion at Havriata and the corresponding acceleration spectral curves from the acceleration components obtained from STRATA software at the bedrock for the three soil profiles.

\section{TWO DIMENSIONAL (2-D) NUMERICAL SIMULATION OF THE SOIL LAYERS, THE CHURCH AND THE BELL TOWER.}

In what follows an 2-D numerical simulation is presented of the soil layers studied in section 2 assuming linear behaviour. Again, three soil layers are numerically simulated with a depth of $10 \mathrm{~m}$ each having mechanical properties the ones listed in Table 1 for soil profile 3. 


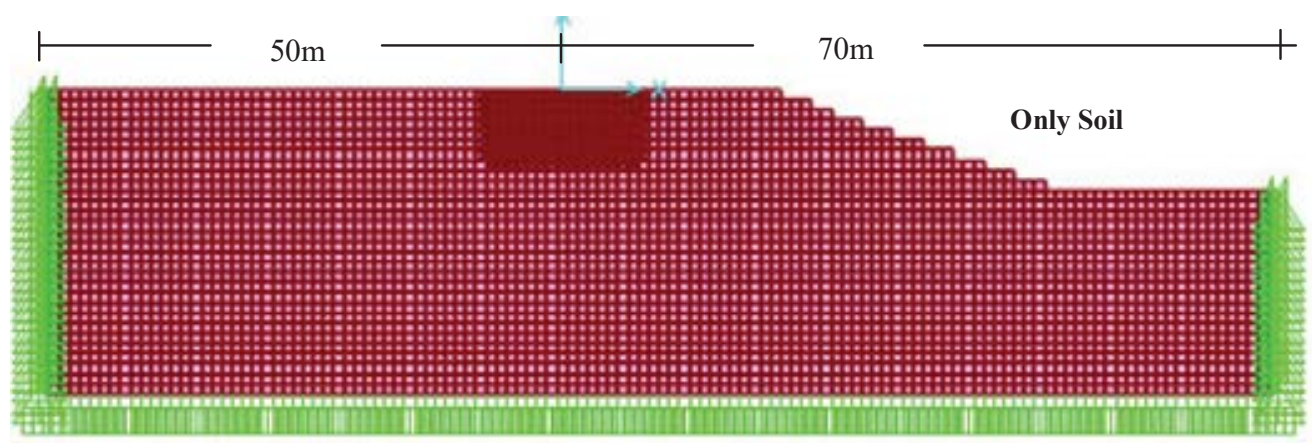

Fig. 10. 2-D Numerical simulation of the soil layers under the bell tower and the church (up to $30 \mathrm{~m}$ depth and $120 \mathrm{~m}$ long)

At the depth of $30 \mathrm{~mm}$ from the surface the boundary is considered with fixed base conditions. At this boundary, the North-South acceleration time history was applied, obtained for the bedrock through STRATA software for soil profile 3, as described in section 3. The length of the soil formation is equal to $120 \mathrm{~m}$, with the vertical boundaries being confined with horizontal links having a finite stiffness of $1000 \mathrm{KN} / \mathrm{mm}$. An attempt is made to numerical simulate the slope of the hill present at the South side of the damaged church at Havriata (see fig 1). An attempt was also made to have a 2-D numerical representation of the bell tower and the church respecting their basic dimensions and the relative distance between them. Moreover, the eigen-period values for the fundamental North-South translational eigen-modes. The dynamic characteristics of these simple representations of either the bell tower or the church are in good agreement with corresponding values found from more detailed 3-D numerical representations of these structures being also partially validated with in-situ measurements.

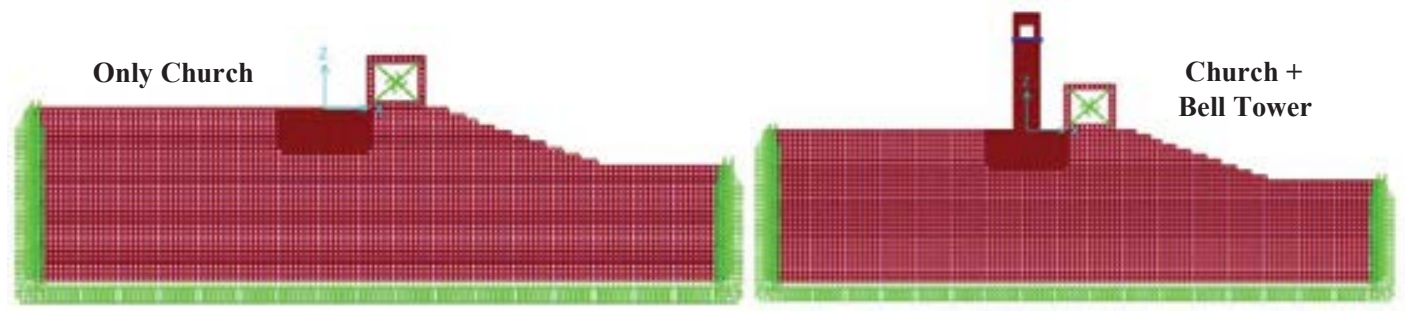

Fig. 11. 2-D Numerical simulation of the soil layers under the bell tower and the church (up to 30m depth) together with simple numerical models of the church, the bell tower and its foundation.

\subsection{Study of eigen-modes and eigen-periods}

In figures 10 and 11 the studied 2-D numerical simulations for the three configurations, namely "only Soil", "only Church" and "Church+Bell Tower" are shown. In all these configurations the numerical simulation of the soil volume remains the same. Moreover, in all the analyses the employed excitation also remains the same, that is bedrock horizontal component that was derived by applying STRATA software for soil profile 3 (linear behaviour - Table 1) using as input the North-South horizontal component of the seismic ground motion recorded in the village of Havriata during the 3rd of February 2014 earthquake sequence (see figure 4).

In what follows first the numerically predicted eigen-modes and eigen-periods are shown for the previously described three configurations. These are presented in the form of a table (Tables 3, 4 and 5) listing the first seven (7) eigen-modes in terms of eigen-period values with the corresponding modal mass participation ratio values. These eigen-modes are with respect 
to one horizontal (x-x) and one vertical (z-z) directions. Figures 13, 14 and 15 depict the corresponding mode-shapes.

\begin{tabular}{c|c|c|c|c|c|}
\hline Only Soil-3 & Period $(\mathbf{s e c})$ & UX \% & UZ \% & SumUX \% & SumUZ \% \\
Mode 1 & $\mathbf{0 , 2 8 9}$ & $\mathbf{3 2 . 0}$ & 0 & 32.0 & 0 \\
Mode 2 & 0,241 & 0.1 & 0 & 32.0 & 0 \\
Mode 3 & 0,202 & 1.0 & 1.2 & 34.0 & 1.2 \\
Mode 4 & $\mathbf{0 , 1 9 6}$ & 0.3 & $\mathbf{2 6 . 0}$ & 34.0 & 28.0 \\
Mode 5 & 0,190 & 0.1 & 4.3 & 34.0 & 32.0 \\
Mode 6 & 0,182 & 0 & 0.9 & 34.0 & 33.0 \\
Mode 7 & 0,177 & 1.3 & 0.7 & 36.0 & 33.0
\end{tabular}

Table 3. Eigen-periods and modal mass participation ratio - Only Soil (Soil-3)

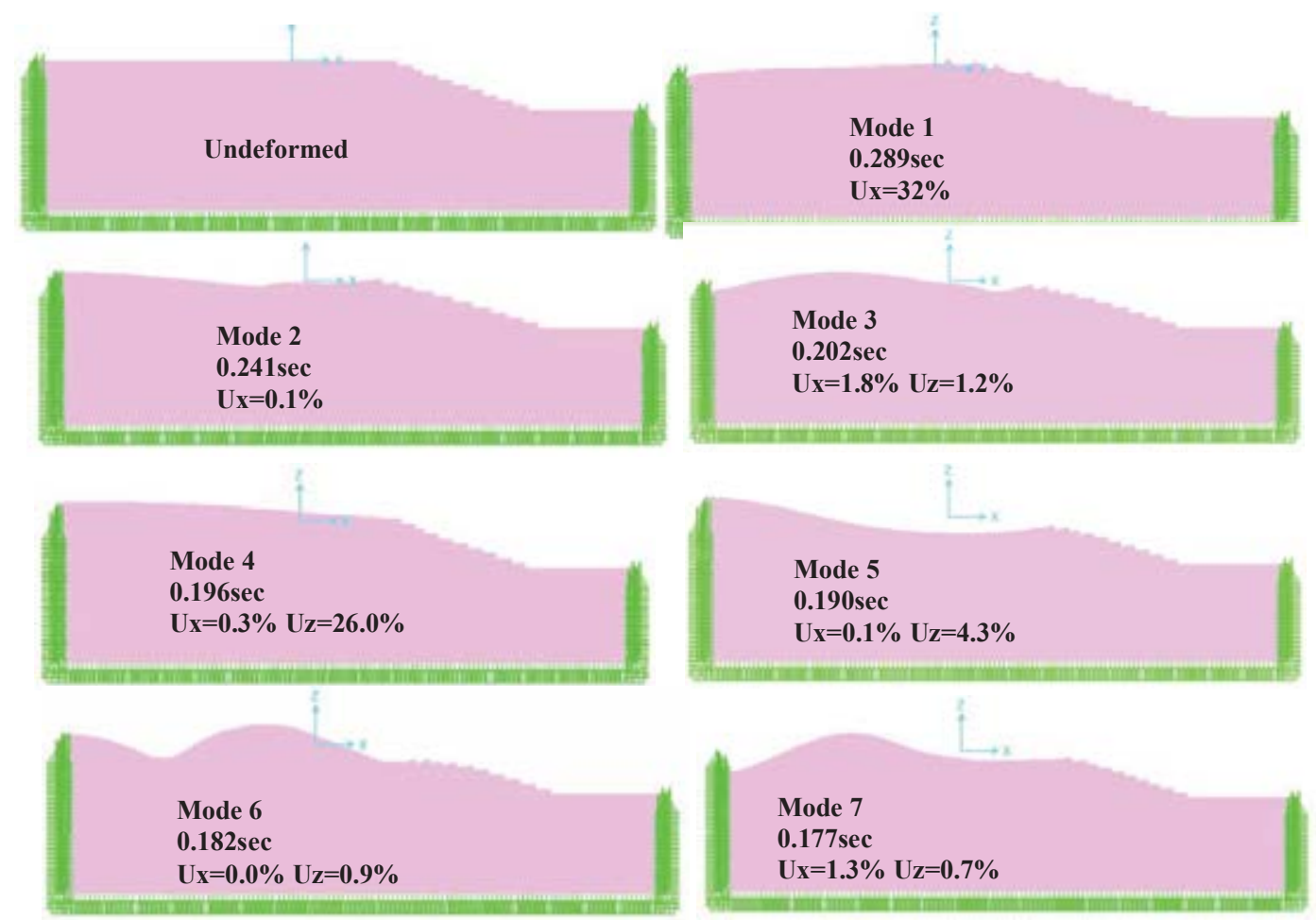

Figure 12. Eigen-modes, eigen-periods and modal mass participation ratio - Only Soil-3

\begin{tabular}{|c|c|c|c|c|c|}
\hline Only Soil-1 & Period $(\mathbf{s e c})$ & UX $\%$ & UZ $\%$ & SumUX \% & SumUZ \% \\
\hline Mode 1 & $\mathbf{0 , 2 0 0}$ & $\mathbf{5 5 . 2}$ & 0.1 & 55.2 & 0.1 \\
Mode 2 & 0,158 & 0.2 & 0 & 55.4 & 01 \\
Mode 3 & $\mathbf{0 , 1 4 1}$ & 0.9 & $\mathbf{4 5 . 8}$ & 56.3 & 45.9 \\
Mode 4 & 0,133 & 1.7 & 5.1 & 57.9 & 51.1 \\
Mode 5 & 0,130 & 0.7 & 0 & 58.6 & 51.1 \\
Mode 6 & 0,118 & 0.7 & 3.9 & 59.4 & 55.0 \\
Mode 7 & $\mathbf{0 , 1 1 2}$ & $\mathbf{1 0 . 5}$ & 0.1 & 69.9 & 55.1
\end{tabular}

Table 4. Eigen-periods and modal mass participation ratio - Only Soil (Soil-1) 


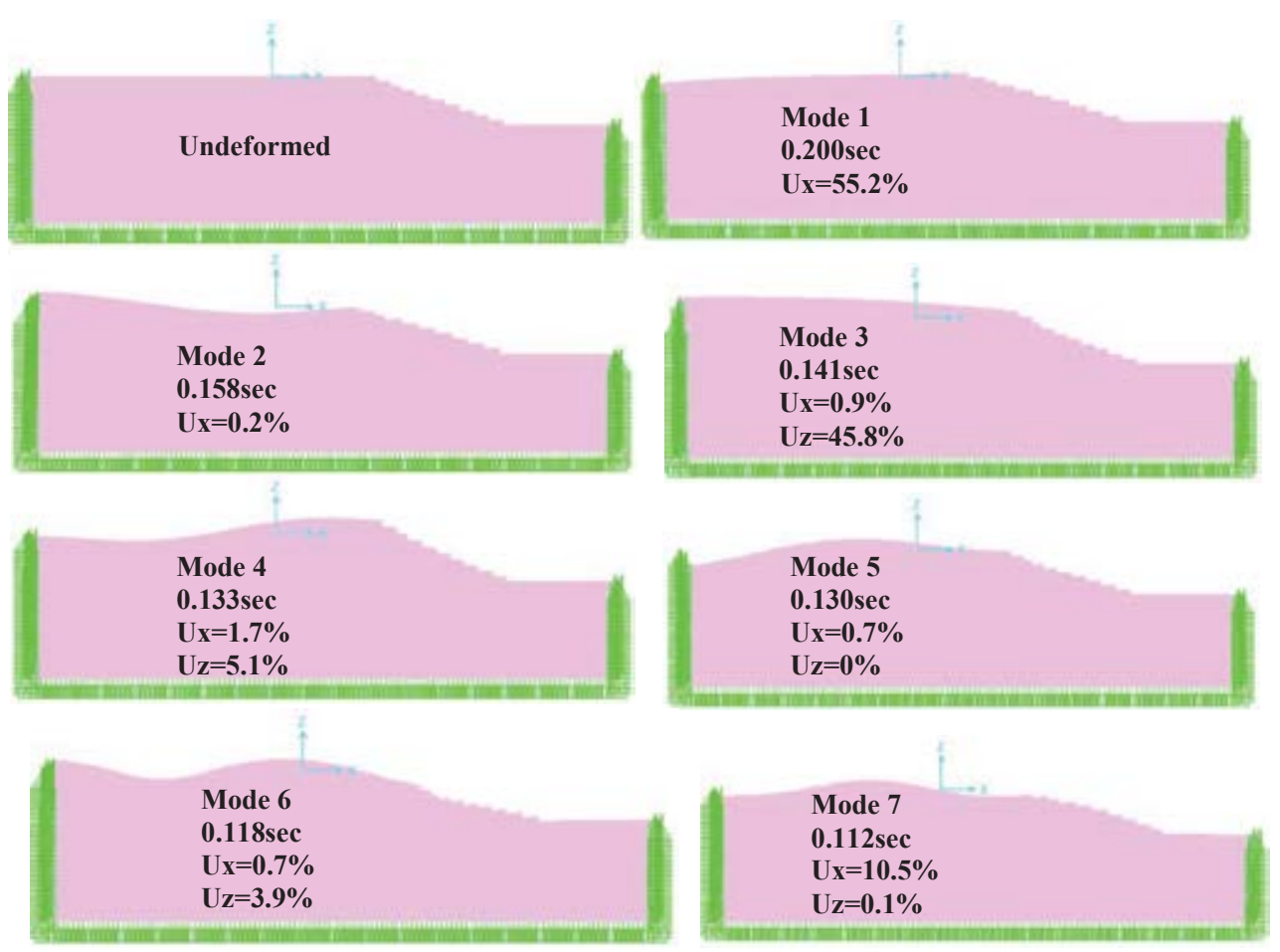

Figure 13. Eigen-modes, eigen-periods and modal mass participation ratio - Only Soil-1

\begin{tabular}{|c|c|cccc|}
\hline Soil-3 + Church & Period $(\mathbf{s e c})$ & UX \% & UZ \% & SumUX \% & SumUZ \% \\
\hline Mode 1 & $\mathbf{0 , 3 0 1}$ & $\mathbf{2 3 . 8}$ & 0 & 23.8 & 0 \\
Mode 2 & 0,267 & 8.1 & 0 & 31.9 & 0 \\
Mode 3 & 0,236 & 0.2 & 0 & 32.1 & 0 \\
Mode 4 & 0,203 & 1.8 & 2.4 & 33.9 & 2.4 \\
Mode 5 & $\mathbf{0 , 1 9 7}$ & 0.4 & $\mathbf{2 9 . 9}$ & 34.3 & 32.4 \\
Mode 6 & 0,193 & 0 & 0.8 & 34.3 & 33.2 \\
Mode 7 & 0,183 & 0.1 & 0.2 & 34.5 & 33.4
\end{tabular}

Table 5. Eigen-periods and modal mass participation ratio - Only Church (Soil-3) 


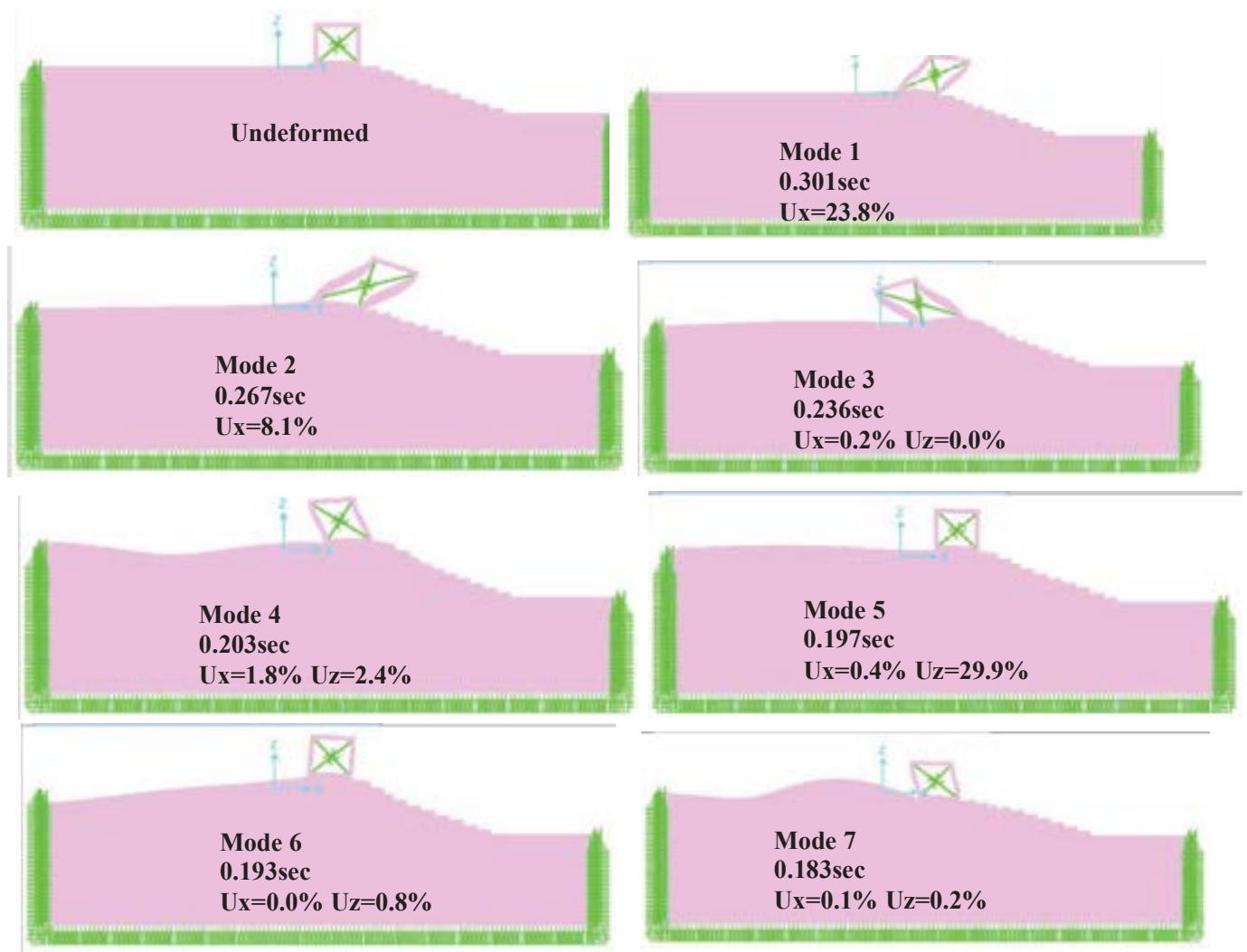

Figure 14. Eigen-modes, eigen-periods and modal mass participation ratio - Church Soil-3

\begin{tabular}{r|c|c|c|c|c}
\hline Soil-1 + Church & Period (sec) & UX $\%$ & UZ $\%$ & SumUX \% & SumUZ \% \\
\hline Mode 1 & 0,232 & 4.5 & 0 & 4.5 & 0 \\
Mode 2 & $\mathbf{0 , 1 9 8}$ & $\mathbf{5 0 . 8}$ & 0.1 & 55.3 & 0.1 \\
Mode 3 & 0,155 & 0.3 & 0 & 55.7 & 0.1 \\
Mode 4 & 0,141 & 0.7 & 0 & 56.4 & 47.9 \\
Mode 5 & $\mathbf{0 , 1 3 4}$ & 1.5 & $\mathbf{4 7 . 8}$ & 57.8 & 51.8 \\
Mode 6 & 0,129 & 1.0 & 0.1 & 58.8 & 51.9 \\
Mode 7 & 0,116 & 0.1 & 3.0 & 59.0 & 54.9
\end{tabular}

Table 6. Eigen-periods and modal mass participation ratio - Church (Soil-1)

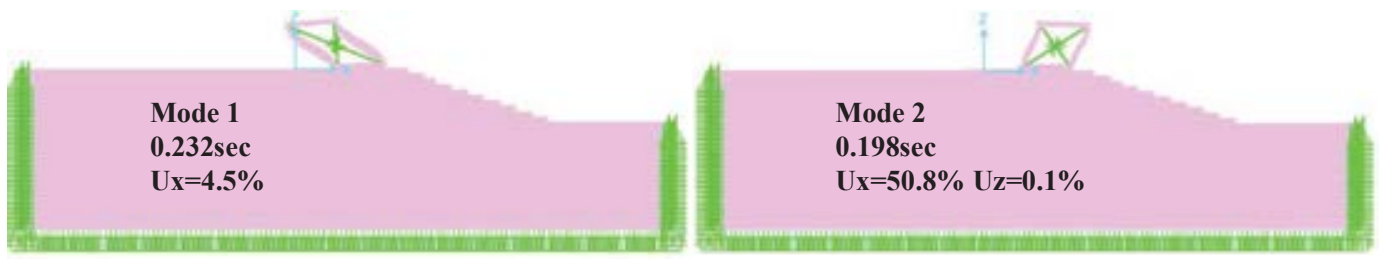

Figure 15. Eigen-modes, eigen-periods and modal mass participation ratio - Church Soil-1 


\begin{tabular}{|c|c|c|c|c|c|}
\hline Soil-3 + Church + Tower & Period (sec) & UX \% & UZ \% & SumUX \% & SumUZ \% \\
\hline Mode 1 & $\mathbf{0 , 3 2 6}$ & $\mathbf{9 . 8}$ & 0 & 9.8 & 0 \\
Mode 2 & $\mathbf{0 , 2 9 4}$ & $\mathbf{1 3 . 2}$ & 0 & 23.0 & 0 \\
Mode 3 & $\mathbf{0 , 2 6 1}$ & $\mathbf{9 . 2}$ & 0 & 32.2 & 0 \\
Mode 4 & 0,231 & 0.5 & 0 & 32.7 & 0 \\
Mode 5 & $\mathbf{0 , 2 0 1}$ & 0.3 & $\mathbf{2 3 . 1}$ & 33.0 & 23.1 \\
Mode 6 & $\mathbf{0 , 1 9 6}$ & 1.6 & $\mathbf{8 . 9}$ & 34.5 & 31.9 \\
Mode 7 & 0,194 & 0 & 0.5 & 34.5 & 32.5
\end{tabular}

Table 7. Eigen-periods and modal mass participation ratio - Church + Bell Tower (Soil-3)

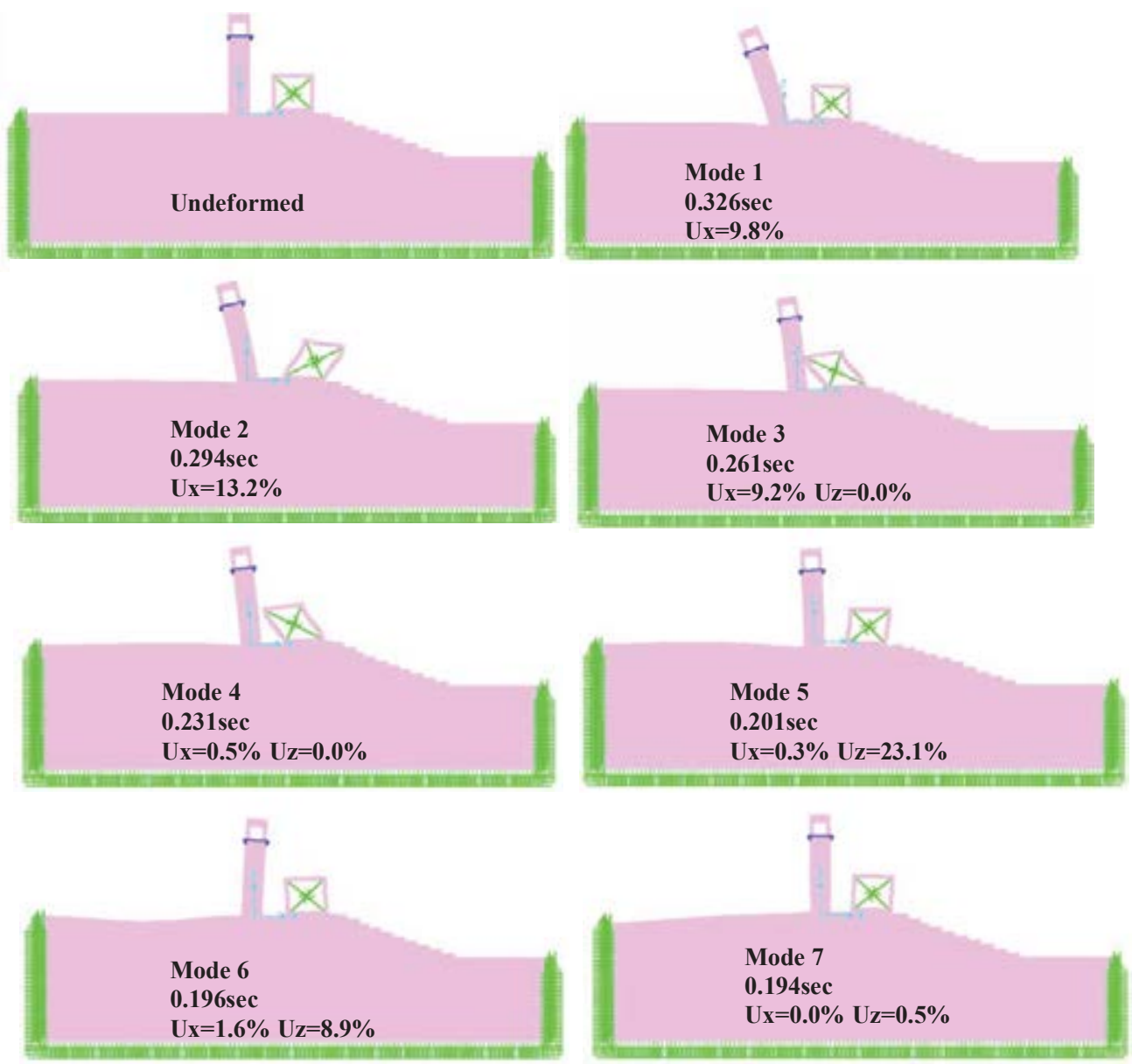

Figure 16. Eigen-modes, eigen-periods and modal mass participation ratio - Church + Bell Tower Soil-3

\begin{tabular}{|c|c|c|c|c|c|}
\hline Soil 1+ Church+Tower & Period (sec) & UX \% & UZ \% & SumUX \% & SumUZ \% \\
\hline Mode 1 & $\mathbf{0 , 2 3 2}$ & 5.4 & 0 & 5.4 & 0 \\
Mode 2 & $\mathbf{0 , 2 1 6}$ & $\mathbf{1 2 . 9}$ & 0 & 18.3 & 0 \\
Mode 3 & $\mathbf{0 , 1 9 3}$ & $\mathbf{3 7 . 3}$ & 0.1 & 55.6 & 0.1 \\
Mode 4 & $\mathbf{0 , 1 5 5}$ & 0.4 & 0 & 56.0 & 0.1 \\
Mode 5 & $\mathbf{0 , 1 4 2}$ & 0.5 & $\mathbf{4 9 . 7}$ & 56.5 & 49.8 \\
Mode 6 & $\mathbf{0 , 1 3 4}$ & 1.1 & 0.9 & 57.6 & 50.7 \\
Mode 7 & $\mathbf{0 , 1 2 8}$ & 1.4 & 0.4 & 59.0 & 51.2
\end{tabular}

Table 8. Eigen-periods and modal mass participation ratio - Church + Bell Tower (Soil-1) 


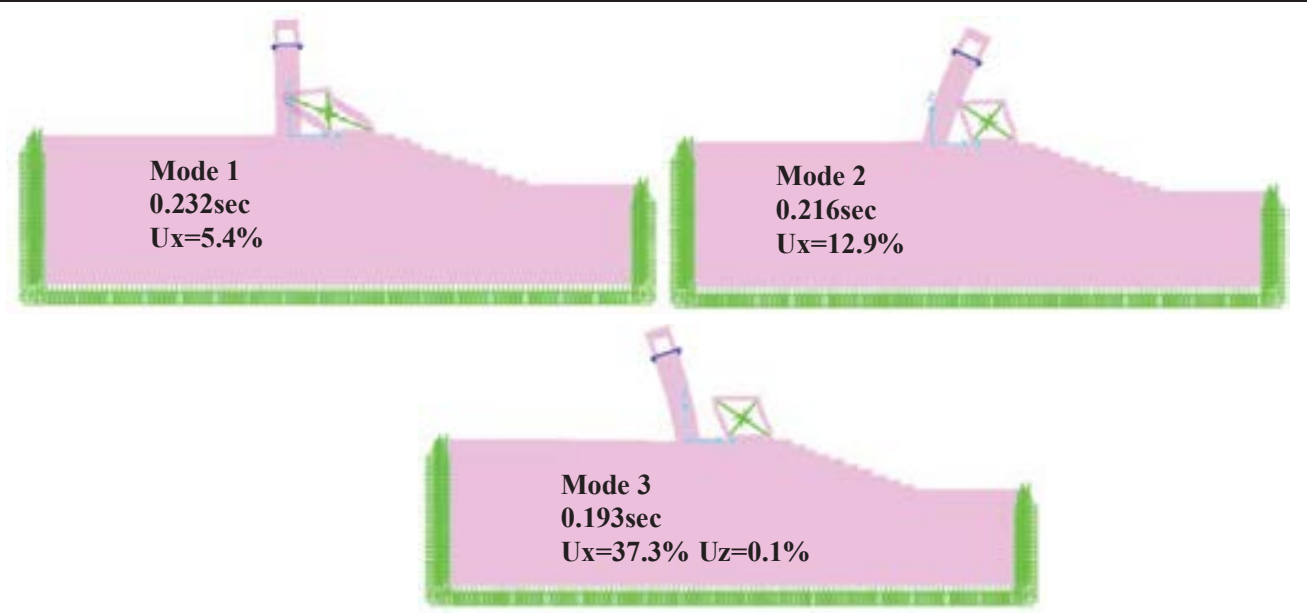

Fig. 17. Eigen-modes, eigen-periods and modal mass participation ratio-Church+Bell Tower (Soil-1)

For soil profile 3 it can be seen from tables 3,5 and 7 and from figures 12, 14 and 16 the main horizontal translational $\mathrm{x}$-x eigen-modes are at $0.3 \mathrm{sec}$ period range whereas the corresponding main vertical $\mathrm{z}-\mathrm{z}$ translational eigen-modes are at the period range of $0.2 \mathrm{sec}$ for all three studied configurations. Both these modes mobilize approximately $30 \%$ of the total mass. For soil profile 1 it can be seen from tables 4,6 and 8 and from figures 13, 15 and 17 the main horizontal translational $\mathrm{x}$-x eigen-modes are at $0.22 \mathrm{sec}$ period range whereas the corresponding main vertical $z-z$ translational eigen-modes are at the period range of $0.14 \mathrm{sec}$ for all three studied configurations. Both these modes mobilize approximately $50 \%$ of the total mass.

\begin{tabular}{|c|c|c|c|}
\hline Only Soil-3 & Period (sec) & UX \% & UZ \% \\
\hline Mode 1 & 0,289 & 32.0 & 0 \\
\hline Mode 4 & 0,196 & 0.3 & 26.0 \\
\hline Soil-3 + Church & Period (sec) & UX \% & UZ \% \\
\hline Mode 1 & 0,301 & 23.8 & 0 \\
\hline Mode 5 & 0,197 & 0.4 & 29.9 \\
\hline Soil-3 + Church+Tower & Period (sec) & UX \% & UZ \% \\
\hline Mode 1 & 0,326 & 9.8 & 0 \\
\hline Mode 2 & 0,294 & 13.2 & 0 \\
\hline Mode 3 & 0,261 & 9.2 & 0 \\
\hline Mode 5 & 0,201 & 0.3 & 23.1 \\
\hline Mode 6 & 0,196 & 1.6 & 8.9 \\
\hline Only Soil-1 & Period (sec) & UX \% & UZ \% \\
\hline Mode 1 & 0,200 & 55.2 & 0.1 \\
\hline Mode 3 & 0,141 & 0.9 & 45.8 \\
\hline Mode 7 & 0,112 & 10.5 & 0.1 \\
\hline Soil-1 + Church & Period (sec) & UX \% & UZ \% \\
\hline Mode 1 & 0,232 & 4.5 & 0 \\
\hline Mode 2 & 0,198 & 50.8 & 0.1 \\
\hline Mode 5 & 0,134 & 1.5 & 47.8 \\
\hline Soil-1 + Church+Tower & Period (sec) & UX \% & UZ \% \\
\hline Mode 1 & 0,232 & 5.4 & 0 \\
\hline Mode 2 & 0,216 & 12.9 & 0 \\
\hline Mode 3 & 0,193 & 37.3 & 0.1 \\
\hline Mode 5 & 0,142 & 0.5 & 49.7 \\
\hline
\end{tabular}

Table 9. Summary of the main eigen-periods and modal mass participation ratio values 


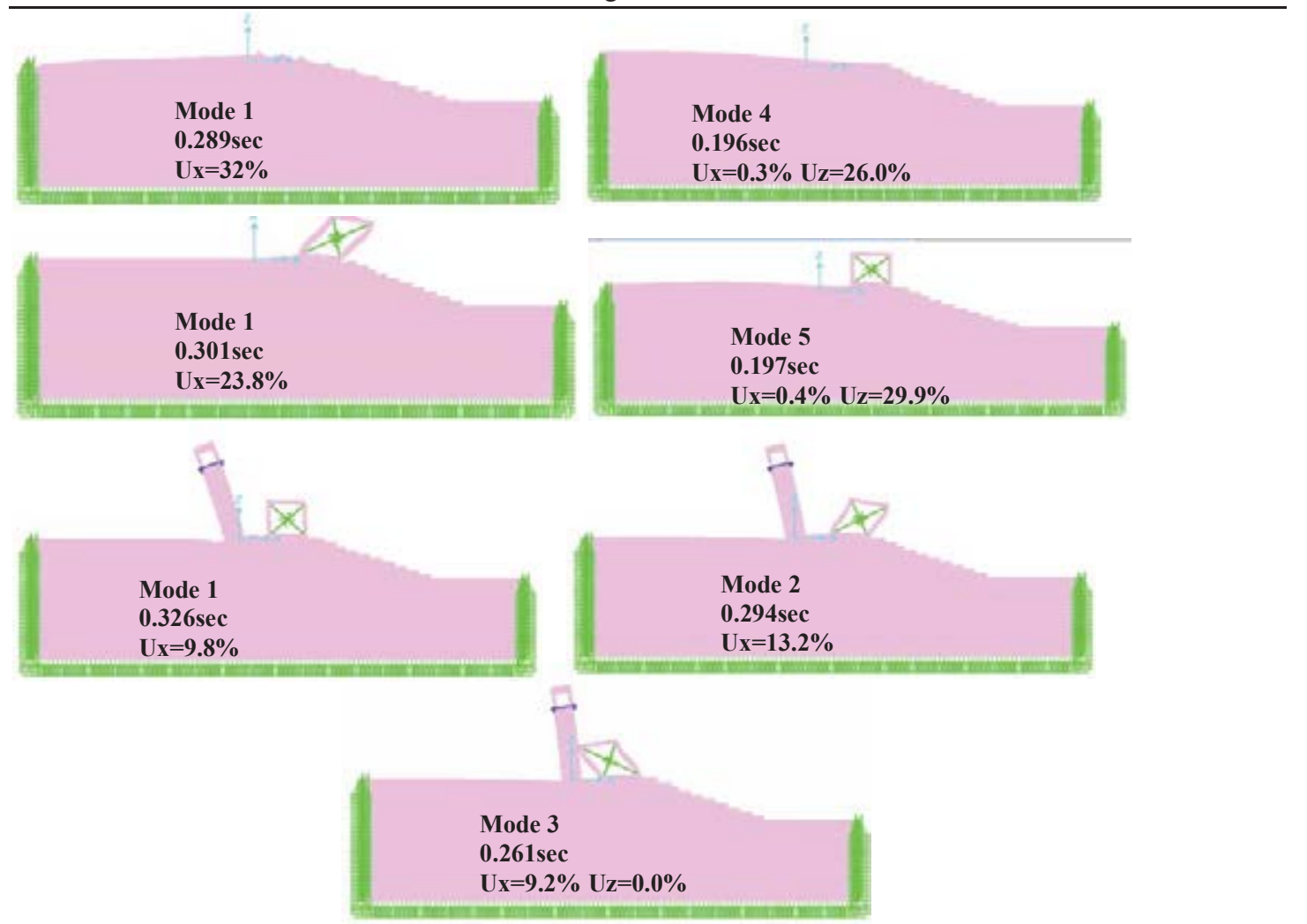

Figure 18. Summary of the main eigen-modes, eigen-periods and modal mass participation ratio - for all three configurations. (Soil-3)

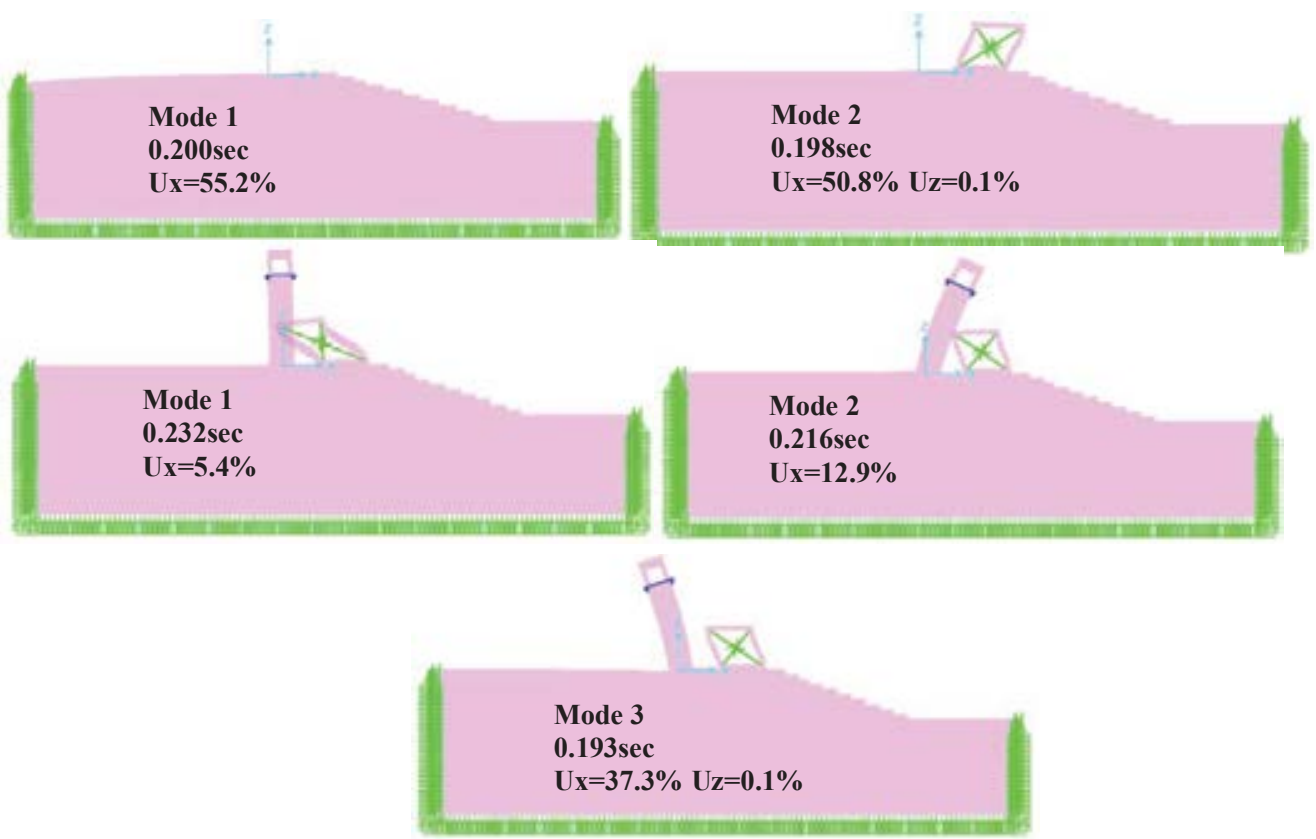

Figure 19. Summary of the main eigen-modes, eigen-periods and modal mass participation ratio - for all three configurations. (Soil-1) 
These eigen-mode and eigen-period results are also summarized in table 9 and figure 18 (Soil profile 3) and figure 19 (Soil profile 1). As can be seen from table 9 and from figures 18 and 19 the presence of the bell tower together with the church introduces a larger number of eigen-modes that participate in a significant way either in the $\mathrm{x}-\mathrm{x}$ or in the $\mathrm{z}-\mathrm{z}$ translation. The values of the eigen-periods of these eigen-modes for the configuration of the "bell tower + church" are quite close to the corresponding period range of either the configuration of "only soil" or the "soil and church". It is also interesting to note that for the configuration of the "bell tower + church" the first translational $\mathrm{x}$-x eigen mode involves mainly the bell tower whereas the second and the third translational $\mathrm{x}$-x eigen-modes involve both the bell tower and the church. As was expected, the eigen-periods of the main eigen-modes or the relatively stiff soil profile (soil-1) have smaller values $(0.22 \mathrm{sec})$ than the corresponding values $(0.3 \mathrm{sec})$ for the relatively flexible soil profile (soil-3). It is interesting to note that for both soil profiles the most significant horizontal translational eigen-modes involve the bell tower together with the church. Therefore, from the study of these eigen-modes it can be concluded that the flexibility of the soil results in vibratory modes coupling both the bell tower and the church. The detrimental effect of the foundation-soil flexibility has been demonstrated in many cases of Greek Orthodox stone masonry churches damaged from past earthquake activity ([19] to [30]).

\section{CONCLUSIONS}

- The increased flexibility of the upper soil layers of the studied soil formation results in the coupling of the dynamic response of the bell tower and the church. This is evident from the study of the significant mode shapes.

- The increased flexibility of the upper soil layers of the studied soil formations and the coupling of the dynamic response of the bell tower and the church results in a vertical acceleration response at the locality between the bell tower and the church which of comparable amplitude to that of the vertical acceleration recorded at the soil surface directly from the seismic event.

- The above conclusions may partly explain the severity of structural damage that was observed at the church of the Panagia Agriliotissa at Havriata, Kefalonia-Greece, as depicted in figure 1 .

- Attention should be given in erecting new bell towers of considerable height at location close to existing masonry churches. The amplification of the seismic response of the church, due to such dynamic coupling effects, could be critical especial for old masonry structures having relatively small resistance to considerable seismic forces, as was the case for the studied church at Havriata.

\section{REFERENCES}

[1] Papazachos, B. and Papazachou, K., 1989, 1997, 2003. The earthquakes of Greece, Zitis Publ., Thessaloniki, 356 pp., 304 pp., 286 pp. (in Greek).

[2] Manos George, "Consequences on the urban environment in Greece related to the recent intense earthquake activity", Int. Journal of Civil Engineering and Architecture, Dec. 2011, Volume 5, No. 12 (Serial No. 49), pp. 1065-1090.

[3] GEER - EERI - ATC - Cephalonia GREECE Earthquake Reconnaissance January 26th/ February 2nd 2014 Version 1: June 62014 
[4] G.C. Manos "The 30th of October Samos-Greece earthquake. Issues relevant to the protection from structural damage caused by strong earthquake ground motions.", Journal of Architecture and Engineering, Vol 5, Issue 4, December 2020, https://aej.spbgasu.ru/index.php/AE

[5] L. de Stefani, R. Scotta, M. Lazzari, A. Saetta. Seismic improvement of Slender Bell Tower and Minarets. - PROHITECH, Antalya, Turkey, 2014

[6] R. M. Azzara, L. Zaccarelli, A. Morelli, T. Trombetti. Seismic Monitoring of the Asinelli and Garisenda Medieval Towers in Bologna (Italy), an Instrumental Contribution to the Engineering Modeling Directed to their Protection. - PROHITECH, Antalya, Turkey, 2014

[7] Casolo Siro, Uva Giuseppina. Non-Linear dynamic analysis of masonry towers under natural accelerograms accounting for soil-structure interaction. - COMPDYN 2013 Kos Island, Greece, June 12-14, 2013

[8] A. Saisi, C. Gentile, L. Cantini. Post - Earthquake assessment of a masonry tower by on -site inspection and operational modal testing. - COMPDYN 2013 - Kos Island, Greece, June 12-14, 2013

[9] D. Colapieto, A.Fiore, A. Netti, F. Fatiguso, G Marano, M. de Fino D. Cascella, A. Antocona. Dynamic identification and evaluation of the seismic safety of a masonry bell tower in the south Italy. - COMPDYN 2013 - Kos Island, Greece, June 12-14, 2013

[10] R. Guidorzi, R. Diversi, L.Vincenzi, C. Mazzotti, V. Simioli. Structural monitoring of the Tower of the Faculty of Engineering in Bologna using MEMS -based sensing. EURODYN 2011 - Leuven, Belgium, 4-6 July 2011

[11] C. Blasi M. Carfagni, S. Carfagni. The use of impulsive actions for the structural identification of Slender monumental buildings- STREMAH-1991 - Seville, Spain, 14-16 May 1991

[12] S. Dumorier, W.P. De Wilde. Finite element study of the Tower of Brussels City Hall STREMAH 1995 - Chania, Crete, Greece, 1995.

[13] G.C. Manos and E. Kozikopoulos, "In-Situ Measured Dynamic Response of the Bell tower of Agios Gerasimos in Lixouri-Kefalonia, Greece and its Utilization in the Numerical Predictions of its Earthquake Response", COMPDYN 2015, 5th ECCOMAS Thematic Conference on, Computational Methods in Structural Dynamics and Earthquake Engineering, Crete Island, Greece, 25-27 May 2015.

[14] G.C. Manos, D. Naxakis, V. Soulis, "The Dynamic and Earthquake Response of a Twostory Old R/C Building with Masonry Infills in Lixouri-Kefalonia, Greece, Including Soil-Foundation Deformability, COMPDYN 2015, 5th ECCOMAS Thematic Conference on, Computational Methods in Structural Dynamics and Earthquake Engineering, Crete Island, Greece, 25-27 May 2015.

[15] G.C. Manos and E. Kozikopoulos "Seismic performance of bell towers in KefaloniaGreece during the 2014 earthquake sequence", 6th ECCOMAS Thematic Conference on Computational Methods in Structural Dynamics and Earthquake Engineering M. Papadrakakis, M. Fragiadakis (eds.) Rhodes Island, Greece, 15-17 June 2017.

[16] George C. Manos, Evaggelos Kozikopoulos, Lambros Kotoulas "In-situ Measurements and Numerical Simulations of the Dynamic and Seismic Response of Bell Towers", 16th European Conf. Earthquake Engineering, Thessaloniki-Greece, 2018. 
[17] Albert R. Kottke and Ellen M. Rathje "Technical Manual for Strata" PEER Report 2008/Pacific Earthquake Engineering Research Center College of Engineering University of California, Berkeley October 2008.

[18] Vucetic \& Dorby, "Effect of Soil Plasticity on Cyclic Response", ASCE, Journal of Geotechnical Engineering, Vol. 117, Issue 1 (January 1991)

[19] G.C. Manos, et al. (1996) "Predictions of the dynamic characteristics of a 5-story R.C. building at the Volvi Euro-SeisTest Site, utilizing low-intensity vibrations", 3rd European Conference on Structural Dynamics, Eurodyn 1996, Florence, II, 877-884.

[20] G. C. Manos, (1998). "The Dynamic Response of a 5-story Structure at the European Test site at Volvi-Greece." 6th U.S. National Earthquake Engineering Conference, May 31 - June 4, Seattle, Washington, U.S.

[21] G. C., Manos, et al.. (2004). "Dynamic and Earthquake Response of Model Structures at the Volvi - Greece European Test Site." 13th World Conference on Earthquake Engineering, Vancouver, Canada.

[22] G. C., Manos, V. Kourtides, V.J. Soulis, A.G. Sextos, A. G., and P. Renault, (2006). "Study of the dynamic response of a bridge pier model structure at the Volvi - Greece European Test Site." 8th National Conference on Earthquake Engineering, April 18-22, San Fransisco, U.S.A.

[23] G.C. Manos, V. Kourtides, A. Sextos, P. Renault, S. Chiras "Study of the dynamic soilstructure interaction of a bridge pier model based on structure and soil measurements" 9th Canadian Conf. on Earthquake Engineering, Ottawa, Ontario, Canada, 26-29 June 2007.

[24] G.C. Manos, V. Kourtides, A. Sextos, S. Chiras "Soil-Foundation-Bridge Pier Interaction at the Euro-Seis Test Site", 4th Int. Conference on Geotechnical Engineering, Thessaloniki, 24-28 June, 2007.

[25] G.C. Manos, V. Kourtides, A. Sextos, "Model Bridge Pier Foundation- Soil Interaction implementing, in-situ / shear stack testing and numerical simulation", 14WCEE, Beijing, CHINA, 2008.

[26] G. C. Manos , K.D. Pitilakis, A.G. Sextos, V. Kourtides, V. Soulis, J. Thauampteh, "Field experiments for monitoring the dynamic soil-structure-foundation response of model structures at a Test Site" Journal of Structural Engineering, American Society of Civil Engineers, Special Issue "Field Testing of Bridges and Buildings, D4014012, Vol. 141, Issue 1, January 2015.

[27] George C. Manos, Evaggelos Kozikopoulos , Lambros Kotoulas, Vasilios Soulis "The Earthquake Performance of Stone Masonry Basilica Churches in Kefalonia, Greece Including Wall Detachement and Foundation Deformability", 16th European Conf. Earthquake Engineering, Thessaloniki-Greece, 2018.

[28] George C. Manos, Lambros Kotoulas and Evangelos Kozikopoulos "Evaluation of the Performance of Unreinforced Stone Masonry Greek "Basilica" Churches When Subjected to Seismic Forces and Foundation Settlement", Journal, buildings, Published: 30 April 2019

[29] Eurocode 8: Design of structures for earthquake resistance - Part 1: General rules, seismic actions and rules for buildings, FINAL DRAFT prEN 1998-1, December 2003. 
[30] G.C. Manos, Seismic Code of Greece, Chapter 17, International Handbook of Earthquake Engineering: "Codes, Programs and Examples", edited by Mario Paz, by Chapman and Hall, ISBN 0-412-98211-0, 1994. 